\title{
Predicting Market Returns Using Aggregate Implied Cost of Capital
}

\author{
Yan Li, David T. Ng, and Bhaskaran Swaminathan ${ }^{1}$
}

First Draft: March 2011

This Draft: November 2012

Theoretically the market-wide implied cost of capital $(I C C)$ is a good proxy for time-varying expected returns. We find that the implied risk premium, computed as $I C C$ minus one-month T-bill yield, strongly predicts future excess market returns ranging from one month to four years. This predictive power persists even in the presence of popular valuation ratios and business cycle variables, both in-sample and out-of-sample, and is robust to alternative implementations and standard errors. Overall, we provide strong evidence of a positive relationship between the $I C C$ and future returns, a key contribution to both the $I C C$ and the predictability literature.

\section{JEL Classification: G12}

Keywords: Implied Cost of Capital, Implied Risk Premium, Market Predictability, Valuation Ratios

\footnotetext{
${ }^{1}$ Yan Li, liyanlpl@temple.edu, Department of Finance, Fox School of Business, Temple University, Philadelphia, PA 19122; David T. Ng, dtn4@cornell.edu, Dyson School of Applied Economics and Management, Cornell University, Ithaca, NY 14853; and Bhaskaran Swaminathan, swami@lsvasset.com, LSV Asset Management, 155 North Wacker Dr., Chicago, IL 60606. We thank Sudipta Basu, Hendrik Bessembinder, Robert Engle, Frank Diebold, Stephan Dieckmann, Wayne Ferson, George Gao, Hui Guo, Jingzhi Huang, Ming Huang, Kewei Hou, Andrew Karolyi, Dana Kiku, Charles Lee, Xi Li, Maureen O'Hara, Robert J. Hodrick, Roger K. Loh, Lilian Ng, Matt Pritsker, David Reeb, Michael Roberts, Oleg Rytchkov, Thomas Sargent, Steve Sharpe, Nick Souleles, Robert F. Stambaugh, Amir Yaron, Yuzhao Zhang, and seminar participants at Cornell University, Journal of Investment Management Conference, Singapore Management University, the Federal Reserve Board, Shanghai Advanced Institute of Finance, Temple University, University of Hong Kong, the Wharton School, and Xiamen University for helpful comments. Finally, we are grateful to Thompson Financial for providing the earnings per share forecast data, available through I/B/E/S. Any errors are our own.
} 


\section{Introduction}

The implied cost of capital $(I C C)$ is the expected return that equates a stock's current price to the present value of its expected future free cash flows where, empirically, the free cash flows are estimated using a combination of short-term analyst earnings forecasts, long-term growth rates projected from the short-term forecasts, and historical payout ratios. ${ }^{2}$ If markets are efficient, the $I C C$ represents the true expected return; if not, it also captures mispricing. The ICC has historically been used to estimate the unconditional equity premium, compute individual firm cost of equity, and address various other cross-sectional asset pricing issues. ${ }^{3}$ Pastor, Sinha, and Swaminathan (2008) use the $I C C$ in a time-series setting and show theoretically that the aggregate market-wide $I C C$ can be a good proxy of time-varying expected returns. They use the aggregate $I C C$ to examine the inter-temporal asset pricing relationship between expected returns and volatility and find a positive relationship between the two. ${ }^{4}$

In this paper, we examine whether the aggregate $I C C$ can also predict future returns on the market, specifically, whether high $I C C$ predicts high returns. This has implications for both the $I C C$ literature and the predictability literature. A key requirement for the usefulness of the $I C C$ is to show that the $I C C$ (positively) predicts future returns. Existing cross-sectional studies on the $I C C$ have been unable to conclusively establish such a positive relationship (see Richardson, Tuna, and Wysocki (2010), Hou, van Dijk, and Zhang (2010), and Plumlee, Botosan, and Wen (2011)). The absence of this evidence, however, might be more due to the noise in computing individual firm $I C C$ s under the various methods used in the literature than due to any theoretical issues with the $I C C$ approach (see Lee, So, and Wang (2010)). The aggregate $I C C$ is likely to be less noisy (since it is computed by averaging individual firm ICCs) and, therefore, might be more successful in predicting future returns. The success of the aggregate $I C C$ in detecting the positive inter-temporal mean-variance relationship (as discussed earlier) is certainly encouraging in this regard.

The $I C C$ also introduces a new measure to the predictability literature, one that is based on a

\footnotetext{
${ }^{2}$ See the next section for details on our implementation.

${ }^{3}$ There is a large literature on the $I C C$. For example, the $I C C$ has been used to study the unconditional equity premium (Claus and Thomas (2001) and Fama and French (2002)), test theories on betas (Kaplan and Ruback (1995), Botosan (1997), Gebhardt, Lee, and Swaminathan (2001), Gode and Mohanram (2003), Brav, Lehavy, and Michaely (2005), and Easton and Monahan (2005)), international asset pricing (Lee, Ng, and Swaminathan (2009)), default risk (Chava and Purnanandam (2010)), asset anomalies (Wu and Zhang (2011)), cross-sectional expected returns (Hou, van Dijk, and Zhang (2010)), stock return volatility (Friend, Westerfield, and Granito (1978)), and the cost of equity (Hail and Leuz (2006), Botosan and Plumlee (2005), Hughes, Liu, and Liu (2009), and Lee, So, and Wang (2010)). Chen, Da, and Zhao (2012) use the $I C C$ as the measure of discount rate, and examine the relative importance of discount rate news and cash flow news in driving stock price movements.

${ }^{4}$ Tests based on realized returns have been inconclusive (see Pastor, Sinha, and Swaminathan (2008)).
} 
theoretically justifiable valuation model that takes into account future growth opportunities that are ignored by traditional valuation ratios such as the dividend yield and the earnings yield. The predictability literature, historically, has had difficulty identifying forecasting variables that can predict future returns both in sample and out-of-sample (see Welch and Goyal (2008)). ${ }^{5}$ Clearly, it would be of interest to know whether the $I C C$ performs better.

We estimate the aggregate $I C C$ as follows. First, we estimate the $I C C$ for each stock in the S\&P 500 index each month (based on membership in the S\&P 500 as of that month). Next, we value-weight the individual $I C C$ s to obtain the aggregate $I C C$. Finally, since the aggregate $I C C$ is in nominal terms, we subtract the one-month T-bill yield from the $I C C$ to compute the implied risk premium, IRP. ${ }^{6}$ We use $I R P$ as our primary measure to forecast future excess market returns.

Using monthly data from January 1977 to December 2011, we find that the implied risk premium is a strong predictor of excess market returns over the next four years, with adjusted $R^{2}$ ranging from $6.6 \%$ at the 1-year horizon to $30.5 \%$ at the 4 -year horizon. Specifically, high IRP predicts high excess returns. The predictive power of $I R P$ remains strong even after we control for widely-used valuation ratios such as the earnings-to-price ratio, dividend-to-price ratio, book-to-market ratio, and the payout yield, business cycle variables such as the term spread, default spread, consumption-towealth ratio, and the investment-to-capital ratio, and other forecasting variables such as measures of investor sentiment, the net equity issuance, inflation, stock market variance, long-term government bond yield, and lagged stock returns. ${ }^{7}$ In contrast, most of the existing forecasting variables including valuation ratios and business cycle variables perform poorly during this sample period.

Since long horizon forecasting regressions are rife with small sample biases, we use rigorous Monte Carlo simulations to assess the statistical significance of our regression statistics. ${ }^{8}$ The

\footnotetext{
${ }^{5}$ For recent debate on the existence of aggregate stock market predictability see, among others, Stambaugh (1986, 1999), Fama and French (1988a), Bekaert and Hodrick (1992), Nelson and Kim (1993), Lamont (1998), Lee, Myers, and Swaminathan (1999), Goyal and Welch (2003), Lewellen (2004), Ang and Bekaert (2007), Boudoukh, Michaely, Richardson, and Roberts (2007), Boudoukh, Richardson, and Whitelaw (2008), Cochrane (2008), Lettau and Nieuwerburgh (2008), Rytchkov (2008), Brennan and Taylor (2010), and Kelly and Pruitt (2011).

${ }^{6}$ The predictions about time-varying expected returns are really about real expected returns. We have two choices: either predict real returns using real $I C C$ or predict excess returns using excess $I C C$, i.e., the implied risk premium. We follow the latter procedure to be consistent with the prior literature. However, we also report robustness tests using real $I C C$ to predict real returns where we simply subtract the monthly inflation rates from monthly nominal $I C C$ s to compute monthly real $I C C \mathrm{~s}$.

${ }^{7}$ A partial list of references include, for valuation ratios: Fama and Schwert (1977), Campbell (1987), Campbell and Shiller (1988), Fama and French (1988a, 1989), Kothari and Shanken (1997), Lamont (1998), Pontiff and Schall (1998), and Boudoukh, Michaely, Richardson, and Roberts (2007); for term spread and default spread: Campbell (1987) and Fama and French (1989); net equity issuance (Baker and Wurgler (2000)); inflation: Nelson (1976), Fama and Schwert (1977) and Campbell and Vuolteenaho (2004); stock market variance: French, Schwert, and Stambaugh (1987) and Guo (2006); long-term government bond yield: Campbell (1987) and Keim and Stambaugh (1986); lagged stock returns (Fama and French (1988b)); consumption-to-wealth ratio (Lettau and Ludvigson (2001)); investmentto-capital ratio (Cochrane (1991)), and the sentiment measures (Baker and Wurgler (2006)).

${ }^{8}$ See, among others, Richardson and Stock (1989), Hodrick (1992), Nelson and Kim (1993), Cavanagh, Elliott, and
} 
predictive power of IRP remains strong even under these stringent simulated $p$-values. We use alternate standard errors that are less biased in small samples (see page 361, Hodrick (1992) and Ang and Bekaert (2007)) and corresponding simulated $p$-values to evaluate the statistical significance of IRP and find that IRP continues to significantly predict future returns. Our findings are also robust to a host of other checks, including alternative ways of constructing IRP and reasonable perturbations in the forecasting horizons of the free cash flow model. ${ }^{9}$ Several studies find that analyst earnings forecasts tend to be optimistic. We construct an aggregate measure of the growth rate implicit in analysts' two-year ahead and one-year ahead earnings forecasts and use it as a proxy of time-varying analyst optimism bias. Our results show that IRP continues to predict future returns significantly even after controlling for the aggregate implied growth rate. ${ }^{10}$

Recently, out-of-sample forecasting tests have received much attention in the literature. Notably, Welch and Goyal (2008) show that estimates of U.S. equity premium based on a simple historical average perform better than a range of widely used predictors in out-of-sample forecasts. We perform a variety of out-of-sample tests and find that IRP is also an excellent out-of-sample predictor of future market excess returns. During 1998-2011 and 2003-2011 (the two periods we use to evaluate the out-of-sample performance), IRP delivers higher and more economically meaningful out-of-sample $R^{2}$ than its competitors and provides positive utility gains of more than $4 \%$ a year to a mean-variance investor. Rapach, Strauss, and Zhou (2010) argue that it is important to combine individual predictors in the out-of-sample setting. We further conduct a forecasting encompassing test, which provides strong evidence that IRP contains distinct information above and beyond that contained in existing predictors.

There are two key reasons for IRP's superior performance: (a) IRP is estimated from a theoretically justifiable discounted cash flow valuation model that takes into account future growth opportunities that are ignored by traditional valuation ratios, and (b) empirically IRP is strongly mean-reverting and hence a better proxy of time-varying expected returns (unit root tests strongly reject the null of a unit root in $I R P$ but not in the traditional valuation measures). In our empirical analysis, we show that IRP is also superior to the forecasted earnings-to-price ratio, which is constructed based on analyst forecasts but does not contain growth beyond the first year. This

Stock (1995), Stambaugh (1999), Torous, Valkanov, and Yan (2004), Campbell and Yogo (2006), Polk, Thompson, and Vuolteenaho (2006), Ang and Bekaert (2007), and Boudoukh, Richardson, and Whitelaw (2008).

${ }^{9}$ We try including and excluding share repurchases, create equal-weighted instead of value-weighted $I R P$, include all stocks instead of just S\&P 500 index stocks, subtract the 30-year treasury yield instead of the 1-month T-bill yield, and use Easton (2004) method to construct IRP. Our results are robust to these alternative specifications. See Section 4.2.4 for more discussions.

${ }^{10} \mathrm{Also}$, we use median analyst forecasts as opposed to mean forecasts in estimating the $I C C$ to reduce the influence of outlier forecasts. 
shows that there is additional information in the long-term growth rates that are projected from the short-term earnings forecasts to estimate the $I C C$.

Overall, our paper makes three key contributions to the literature: (a) we provide strong evidence in favor of aggregate stock market predictability, (b) we introduce a new forecasting variable, the $I C C$, which forecasts future returns better than existing forecasting variables both in sample and out-of-sample, and (c) we validate the usefulness of the $I C C$ approach by showing that the $I C C$ can positively predict future returns.

Finally, our paper also sheds some light on the risk vs. mispricing debate on the predictability of returns. The ICC measures the discount rate implicitly used by the market to arrive at the current price. As discussed earlier, if markets are not efficient, the $I C C$ can also contain a mispricing component. Our multivariate tests show that IRP strongly predicts future returns even after controlling for a host of business cycle proxies including the consumption-to-wealth ratio. This suggests that at least some of the predictive power of IRP could be due to mispricing, i.e., IRP is low when the market is overvalued and high when the market is undervalued.

Our paper proceeds as follows. We describe the methodology for constructing the aggregate $I C C$ and IRP in Section 2. Section 3 provides the data source and summary statistics. Section 4 and Section 5 present the in-sample and out-of-sample return predictions, respectively. Section 6 concludes the paper.

\section{Empirical Methodology}

In this section, we first explain why the implied cost of capital is a good proxy for expected returns. We then describe the construction of the implied cost of capital.

\subsection{ICC as a Measure of Expected Return}

The implied cost of capital is the value of $r_{e}$ that solves the infinite horizon dividend discount model:

$$
P_{t}=\sum_{k=1}^{\infty} \frac{E_{t}\left(D_{t+k}\right)}{\left(1+r_{e}\right)^{k}}
$$

where $P_{t}$ is the stock price and $D_{t}$ is the dividend at time $t$.

Campbell, Lo, and MacKinlay (1996)(7.1.24) provide a log-linear approximation of the dividend discount model which allows us to express the log dividend-price ratio as:

$$
d_{t}-p_{t}=-\frac{k}{1-\rho}+E_{t}\left(\sum_{j=0}^{\infty} \rho^{j} r_{t+1+j}\right)-E_{t}\left(\sum_{j=0}^{\infty} \rho^{j} \triangle d_{t+1+j}\right),
$$


where $r_{t}$ is the log stock return at time $t, d_{t}$ is the log dividends at time $t$, and $\rho=1 /(1+\exp (\overline{d-p})$, $k=\log (\rho)-(1-\rho) \log (1 / \rho-1)$, and $\overline{d-p}$ is the average log dividend-to-price ratio. From equation $(2)$, it is natural to define the $I C C$ as the value of $r_{e, t}$ that solves

$$
d_{t}-p_{t}=-\frac{k}{1-\rho}+r_{e, t} E_{t}\left(\sum_{j=0}^{\infty} \rho^{j}\right)-E_{t}\left(\sum_{j=0}^{\infty} \rho^{j} \triangle d_{t+1+j}\right),
$$

and thus

$$
r_{e, t}=k+(1-\rho)\left(d_{t}-p_{t}\right)+(1-\rho) E_{t}\left(\sum_{j=0}^{\infty} \rho^{j} \triangle d_{t+1+j}\right) .
$$

Therefore, the $I C C$ contains information about both the dividend yield and future dividend growth. Pastor, Sinha, and Swaminathan (2008) show theoretically that $I C C$ is an excellent proxy of timevarying expected returns and use it empirically to detect the inter-temporal asset pricing relationship between expected returns and volatility.

\subsection{Construction of the Firm-Level ICC}

We compute the firm-level $I C C$ as the internal rate of return that equates the present value of future dividends/free cash flows to the current stock price, following the approach of Pastor, Sinha, and Swaminathan (2008). We use the term "dividends" interchangeably with free cash flows to equity (FCFE) to describe all cash flows available to equity.

There are two key assumptions in our empirical implementation of the free cash flow model: (a) short-run earnings growth rates converge in the long-run to the growth rate of the overall economy and (b) competition will drive economic profits on new investments to zero in the long-run (the marginal rate of return on investment - the ROI on the next dollar of investment - will converge to the cost of capital). As explained below, we use these assumptions to forecast earnings growth rates and free cash flows during the transition from the short-run to the long-run steady-state.

To implement equation (1), we need to explicitly forecast free cash flows for a finite horizon. We do this in two parts: i) the present value of free cash flows up to a terminal period $t+T$, and ii) a continuing value that captures free cash flows beyond the terminal period. We estimate free cash flows up to year $t+T$, as the product of annual earnings forecasts and one minus the plowback rate:

$$
E_{t}\left(F C F E_{t+k}\right)=F E_{t+k} \times\left(1-b_{t+k}\right)
$$

where $F E_{t+k}$ and $b_{t+k}$ are the earnings forecasts and the plowback rate forecasts for year $t+k$, respectively. 
We forecast earnings up to year $t+T$ in three stages. (i) We explicitly forecast earnings (in dollars) for year $t+1$ using analyst forecasts. I/B/E/S analysts supply earnings per share (EPS) forecasts for the next two fiscal years, $F Y_{1}$, and $F Y_{2}$ respectively, for each firm in the I/B/E/S database. We construct a 12-month ahead earnings forecast $F E_{1}$ using the median $F Y_{1}$ and $F Y_{2}$ forecasts such that $F E_{1}=w \times F Y_{1}+(1-w) \times F Y_{2}$, where $w$ is the number of months remaining until the next fiscal year-end divided by 12 . We use median forecasts instead of mean in order to alleviate the effects of extreme forecasts especially on the optimistic side by individual analysts. (ii) We then use the growth rate implicit in $F Y_{1}$ and $F Y_{2}$ to forecast earnings for $t+2$; that is, $g_{2}=F Y_{2} / F Y_{1}-1$, and the two-year-ahead earnings forecast is given by $F E_{2}=F E_{1}\left(1+g_{2}\right)$. Constructing $F E_{1}$ and $F E_{2}$ in this way ensures a smooth transition from $F Y_{1}$ to $F Y_{2}$ during the fiscal year and also ensures that our forecasts are always 12 months and 24 months ahead from the current month. ${ }^{11}$ Firms with growth rates above $100 \%$ (below 2\%) are given values of $100 \%$ (2\%). (iii) We forecast earnings from year $t+3$ to year $t+T+1$ by assuming that the year $t+2$ earnings growth rate $g_{2}$ mean-reverts exponentially to steady-state values by year $t+T+2$. We assume that the steady-state growth rate starting in year $t+T+2$ is equal to the long-run nominal GDP growth rate, $g$, computed as a rolling average of annual nominal GDP growth rates. Specifically, earnings growth rates and earnings forecasts using the exponential rate of mean reversion are computed for years $t+3$ to $t+T+1$ as follows $(k=3, \ldots, T+1)$ :

$$
\begin{aligned}
g_{t+k} & =g_{t+k-1} \times \exp \left[\log \left(g / g_{2}\right) / T\right] \text { and } \\
F E_{t+k} & =F E_{t+k-1} \times\left(1+g_{t+k}\right) .
\end{aligned}
$$

The exponential rate of mean-reversion is just linear interpolation in logs and provides a more rapid rate of mean reversion for very high growth rates. We forecast plowback rates using a two-stage approach. (i) We explicitly forecast plowback rate for years $t+1$ as one minus the most recent years dividend payout ratio. We estimate the dividend payout ratio by dividing actual dividends from the most recent fiscal year by earnings over the same time period. ${ }^{12}$ In our primary approach, we exclude share repurchases and new equity issues due to the practical problems associated with determining the likelihood of their recurrence in future periods. Payout ratios of less than zero

\footnotetext{
${ }^{11}$ In addition to $F Y_{1}$ and $F Y_{2}$, I/B/E/S also provides the analysts forecasts' of the long-term earnings growth rate $(L t g)$. An alternative way of obtaining $g_{2}$ is to use $L t g$. In untabulated results, we show that $g_{2}=F Y_{2} / F Y_{1}-1$ is a better measure than $g_{2}=L t g$, because the former is a better predictor of the actual earnings' growth rate in year $t+2$.

${ }^{12}$ If earnings are negative, the plowback rate is computed as the median ratio across all firms in the corresponding industry-size portfolio. The industry-size portfolios are formed each year by first sorting firms into 49 industries based on the Fama-French classification and then forming three portfolios with an equal number of firms based on their market cap within each industry.
} 
(greater than one) are assigned a value of zero (one). (ii) We assume that the plowback rate in year $t+1, b_{1}$, reverts linearly to a steady-state value by year $t+T+1$ computed from the sustainable growth rate formula. This formula assumes that, in the steady state, the product of the return on new investments and the plowback rate $R O E * b$ is equal to the growth rate in earnings $g$. We further impose the condition that, in the steady state, $R O E$ equals $r_{e}$ for new investments, because competition will drive returns on these investments down to the cost of equity.

Substituting $R O E$ with cost of equity $r_{e}$ in the sustainable growth rate formula and solving for plowback rate $b$ provides the steady-state value for the plowback rate, which equals the steady-state growth rate divided by the cost of equity $g / r_{e}$. The intermediate plowback rates from $t+2$ to $t+T$ $(k=2, \ldots, T)$ are computed as follows:

$$
b_{t+k}=b_{t+k-1}-\frac{b_{1}-b}{T}
$$

The terminal value $T V$ is computed as the present value of a perpetuity, which is equal to the ratio of the year $t+T+1$ earnings forecast divided by the cost of equity:

$$
T V_{t+T}=\frac{F E_{t+T+1}}{r_{e}},
$$

where $F E_{t+T+1}$ is the earnings forecast for year $t+T+1 .{ }^{13}$ It is easy to show that the Gordon growth model for $T V$ will simplify to equation (6) when $R O E$ equals $r_{e}$.

Substituting equations (3) to (6) into the infinite-horizon free cash flow valuation model in equation (1) provides the following empirically tractable finite horizon model:

$$
P_{t}=\sum_{k=1}^{T} \frac{F E_{t+k} \times\left(1-b_{t+k}\right)}{\left(1+r_{e}\right)^{k}}+\frac{F E_{t+T+1}}{r_{e}\left(1+r_{e}\right)^{T}} .
$$

Following Pastor, Sinha, and Swaminathan (2008), we use a 15-year horizon $(T=15)$ to implement the model in (7) and compute $r_{e}$ as the rate of return that equates the present value of free cash flows to the current stock price. To be consistent, the stock price is also obtained from the I/B/E/S database as of the same date as the I/B/E/S earnings forecasts. The resulting $r_{e}$ is the firm-level $I C C$ measure used in our empirical analysis.

\footnotetext{
${ }^{13}$ Note that the use of the no-growth perpetuity formula does not imply that earnings or cash flows do not grow after period $t+T$. Rather, it simply means that any new investments after year $t+T$ earn zero economic profits. In other words, any growth in earnings or cash flows after year $T$ is value-irrelevant.
} 


\subsection{Construction of the Aggregate $I C C$}

Each month, the value-weighted aggregate $I C C$ is constructed as follows:

$$
I C C_{t}=\sum_{i=1}^{n} \frac{v_{i, t}}{\sum_{i=1}^{n} v_{i, t}} I C C_{i, t},
$$

where $i$ indexes firm, and $t$ indexes time. $v_{i, t}$ is the market value for firm $i$ at time $t$, and $I C C_{i, t}$ is the $I C C$ for firm $i$ at time $t$. We construct the value-weighted aggregate $I C C$ using firms in the $\mathrm{S} \& \mathrm{P}$ 500 , but we also conduct a variety of robustness checks in Section 4.2.4 based on ICC s constructed using the firms in the Dow Jones Industrial Average (DJIA) or all firms in NYSE/AMEX/Nasdaq. To mitigate the impact of outliers, each month we delete extreme $I C C$ s which lie outside the five standard deviations of their monthly cross-sectional distributions. However, the results are robust to not trimming outliers.

In predicting future returns there are two choices: (a) use real $I C C$ to predict real returns, or (b) use excess $I C C$, i.e., the implied risk premium $(I R P)$ which is $I C C$ minus the risk-free rate to predict excess returns. In this paper, consistent with prior literature, we forecast excess returns using the IRP. The IRP is computed by subtracting the one-month T-bill yield (Tbillyield) from the aggregate $I C C$ :

$$
I R P_{t}=I C C_{t}-\text { Tbillyield }_{t}
$$

We also perform robustness tests in Section 4.2.4 based on a IRP computed by subtracting the 30-year treasury yield.

\section{$3 \quad$ Data and Summary Statistics}

We compute the aggregate $I C C$ and $I R P$ at the end of every month from January 1977 to December 2011 using all firms that belong to the S\&P 500 index as of the given month. We obtain market capitalization and return data from CRSP, accounting data such as common dividends, net income, book value of common equity, and fiscal year-end date from COMPUSTAT, and analyst earnings forecasts and share price from I/B/E/S. To ensure we only use publicly available information, we obtain accounting data items for the most recent fiscal year ending at least 3 months prior to the month-end when the $I C C$ is computed. Data on nominal GDP growth rates are obtained from the Bureau of Economic Analysis. Our GDP data begins in 1930. Each year, we compute the steady-state GDP growth rate as the historical average of the GDP growth rates using annual data up to that year. 
We use the CRSP NYSE/AMEX/Nasdaq value-weighted returns including dividends from WRDS as our primary measure of aggregate market returns (Vwretd). ${ }^{14}$ We compare the performance of IRP to a long list of forecasting variables that have been proposed in the literature. The most important group represents the traditional valuation ratios: dividend-to-price-ratio $(D / P)$, earnings-to-price ratio $(E / P)$, and book-to-market ratio $(B / M)$. Whether these valuation ratios predict future returns, especially after taking into account various econometric issues with predictive regressions (e.g., Boudoukh, Richardson, and Whitelaw (2008), Cochrane (2008)), is still open to debate. In addition to standard valuation ratios, we also consider other commonly used predictors which are listed below. Just like the $I C C$, all monthly predictors are computed as of the end of the month.

- Dividend-to-price-ratio $(D / P)$ is the value-weighted average of firm-level dividend-to-price ratios for the $\mathrm{S} \& \mathrm{P} 500$ firms, where the firm-level $D / P$ is obtained by dividing the total dividends from the most recent fiscal year end (ending at least 3 months prior) by market capitalization at the end of the month. ${ }^{15}$

- Earnings-to-price ratio $(E / P)$ is the value-weighted average of firm-level earnings-to-price ratios for the $\mathrm{S} \& \mathrm{P} 500$ firms, where the firm-level $E / P$ is obtained by dividing earnings from the most recent fiscal year end (ending at least 3 months prior) by market capitalization at the end of the month.

- Book-to-market ratio $(B / M)$ is the value-weighted average of firm-level ratio of book value to market value for the $\mathrm{S} \& \mathrm{P} 500$ firms, where the firm-level $B / M$ is obtained by dividing the total book value of equity from the most recent fiscal year end (ending at least 3 months prior) by market capitalization at the end of the month.

- Payout Yield $(P / Y)$ is the sum of dividends and repurchases divided by contemporaneous year-end market capitalization (Boudoukh, Michaely, Richardson, and Roberts (2007)), obtained from Michael R. Roberts' website.

- Default spread (Default) is the difference between BAA and AAA rated corporate bond yields, obtained from the economic research database at the Federal Reserve Bank at St. Louis (FRED).

- Term spread (Term) is the difference between AAA rated corporate bond yields and the one-month T-bill yield, where the one-month T-bill yield is the average yield on one-month Treasury bill obtained from WRDS.

- T-bill rate (Tbill) is the one-month T-bill rate obtained from Kenneth French's website.

- Long-term treasury yield (Yield) is the 30-year treasury yield obtained from WRDS.

- Net equity expansion (ntis) is the ratio of new equity issuance to the sum of new equity and debt issuance (Baker and Wurgler (2000)), with data obtained from Jeffrey Wurgler's website.

\footnotetext{
${ }^{14}$ Results based on other measures of the aggregate market return such as the S\&P 500 return yield similar results.

${ }^{15}$ Fama and French (1988a) construct $D / P$ based on the value-weighted market return with and without dividends. This alternative measure of $D / P$ has a correlation of 0.96 with our constructed measure, and yields very similar results.
} 
- Inflation (infl) is the change in CPI (all urban consumers) obtained from FRED.

- Stock variance (svar) is the sum of squared daily returns on the S\&P 500 index with data obtained from WRDS.

- Lagged excess market returns (Lagged Vwretd) is the lagged value-weighted market return including dividends from WRDS subtracting the one-month T-bill rate.

- Sentiment index (senti) is the first principal component of six sentiment proxies (Baker and Wurgler (2006)), with data obtained from Jeffrey Wurgler's website. ${ }^{16}$

- Consumption-to-wealth ratio (cay) is the cointegrating residual from a regression of log consumption on log asset (nonhuman) wealth, and log labor income (Lettau and Ludvigson (2001)), with data obtained from Martin Lettau's website.

- Investment-to-capital ratio $(i / k)$ is the ratio of aggregate (private nonresidential fixed) investment to aggregate capital for the entire economy (Cochrane (1991)), obtained from Amit Goyal's website.

We have monthly data for $P / Y$, ntis, infl, svar, Lagged Vwretd, and senti from January 1977 to December 2010, and quarterly data for cay and $i / k$ from 1977.Q1 to 2008.Q4. ${ }^{17}$ All other variables have monthly data from January 1977 to December 2011. It is also worth noting that $P / Y$ is provided in logarithm.

\section{[INSERT TABLE 1 HERE]}

Table 1 presents univariate summary statistics for all forecasting variables. Panel A shows that the average annualized $I R P$ is $7.07 \%$ and its standard deviation is $2.68 \%$. The first order autocorrelation of IRP is 0.95 which declines to 0.10 after 24 months, and to -0.20 after 36 months. In contrast, the valuation ratios $E / P, D / P$, and $B / M$ are much more persistent, with first-order autocorrelations between 0.98 and 0.99 that hover above 0.40 even after 60 months. Appendix A shows that unit root tests strongly reject the null of a unit root for $I R P$, but not for the valuation ratios. Clearly, IRP is a much more stationary process that exhibits faster mean reversion. Panel A shows that the ex post risk premium computed from value-weighted excess market returns (this is not continuously compounded; we use continuously compounded returns only in the regressions), Vwretd, is $6.66 \%$ which is comparable to the average IRP of $7.07 \%$. The sum of autocorrelations at long horizons are negative for Vwretd which suggests there is long-term mean reversion in stock returns.

\footnotetext{
${ }^{16}$ The six sentiment proxies include the closed-end fund discount, NYSE share turnover, the number of IPOs, the average first-day IPO returns, the share of equity issuance, and the dividend premium. There is a second sentiment index which is the principal component of the six sentiment proxies orthoganalized to variables measuring business cycles. The correlation between the two sentiment indices is 0.96 , and they yield very similar results. So we only include the first index in our analysis.

${ }^{17}$ Although our data on Lagged Vwretd end in December 2011, we use the data from January 1977 to December 2010 to be consistent with the length of svar in our multivariate regression (see Section 4.2.3).
} 
In Panel $\mathrm{B}, I R P$ is positively correlated with each of the valuation ratios, which suggests that they share common information about time-varying expected returns. IRP is also significantly positively correlated with Term and Default, which suggests that IRP also varies with the business cycle. The high negative correlation $(-0.66)$ between IRP and $i / k$ (Panel D) suggests that the aggregate investment in the economy drops as the cost of capital rises. This is intuitive and as expected. Overall, the summary statistics in Table 1 indicate that the $I C C$ has intuitive appeal as a measure of time-varying expected return.

\section{[INSERT FIGURE 1 HERE]}

Figure 1 plots IRP over time, together with its median and two-standard-deviation bands calculated based on the median using all historical data starting from January 1987. It also marks the NBER recession periods in shaded areas and some notable dates and the risk premia on those dates. Overall, consistent with existing theories (e.g., Campbell and Cochrane (1999); Barberis, Huang, and Santos (2001)), there is some evidence of a countercyclical behavior on the part of IRP especially during recessions when it tends to be high. The implied risk premium reached a high of $12.8 \%$ in March 2009 at the depth of the market downturn. At the end of 2011, the implied risk premium was still a high $9.7 \%$.

[INSERT FIGURE 2 HERE]

Figure 2 plots $D / P, E / P, B / M$, and $P / Y$. The plots suggest that there is some commonality in the way these valuation ratios vary over time. IRP in Figure 1 appears more stationary than these valuation ratios, which is also confirmed by the unit root tests in Appendix A.

\section{In-sample Return Predictions}

\subsection{Forecasting Regression Methodology}

We begin with the multiperiod forecasting regression test in Fama and French (1988a,b, 1989):

$$
\sum_{k=1}^{K} \frac{r_{t+k}}{K}=a+b \times X_{t}+u_{t+K, t}
$$

where $r_{t+k}$ is the continuously compounded excess return per month defined as the difference between the monthly continuously compounded return on the value-weighted market return including 
dividends from WRDS and the monthly continuously compounded one-month T-bill rate (i.e., continuously compounded Vwretd). ${ }^{18}$ Quarterly returns are defined in the same way. $X_{t}$ is a $1 \times k$ row vector of explanatory variables (excluding the intercept), $b$ is a $k \times 1$ vector of slope coefficients, $K$ is the forecasting horizon, and $u_{t+K, t}$ is the regression residual.

We conduct these regressions for different horizons: in monthly regressions, $K=1,12,24$, 36 , and 48 months, and in quarterly regressions, $K=1,4,8,12$, and 16 quarters. One problem with this regression test is the use of overlapping observations, which induces serial correlation in the regression residuals. Specifically, under both the null hypothesis of no predictability and the alternative hypotheses that fully account for time-varying expected returns, the regression residuals are autocorrelated up to lag $K-1$. As a result, the regression standard errors from ordinary least squares (OLS) would be too low and the $t$-statistics too high. Moreover, the regression residuals are likely to be conditionally heteroskedastic. We correct for both the induced autocorrelation and the conditional heteroskedasticity following Hansen (1982). Under generalized method of moments, the GMM estimator $\theta=(a, b)$ has an asymptotic distribution $\sqrt{T}(\widehat{\theta}-\theta) \sim N(0, \Omega)$, where $\Omega=$ $Z_{0}^{-1} S_{0} Z_{0}^{-1}, Z_{0}=E\left(x_{t} x_{t}^{\prime}\right)$, with $x_{t}=\left(1 X_{t}^{\prime}\right)^{\prime}$, and $S_{0}$ is the spectral density evaluated at frequency zero of $\omega_{t+K}=u_{t+K, t} x_{t}$. Under the null hypothesis that returns are not predictable,

$$
S_{0}=\sum_{j=-K+1}^{K-1} E\left(\omega_{t+K} \omega_{t+K-j}^{\prime}\right) .
$$

In our main empirical analysis, we estimate $S_{0}$ using the Newey-West correction (Newey and West (1987)) with $K-1$ moving average lags.

We call the resulting test statistic the asymptotic $Z$-statistic. Since the forecasting regressions use the same data at various horizons, the regression slopes will be correlated. It is, therefore, not correct to draw inferences about predictability based on any one regression. To address this issue, Richardson and Stock (1989) propose a joint test based on the average slope coefficient. Following their paper, we compute the average slope statistic, which is the arithmetic average of regression slopes across different horizons, to test the null hypothesis that the slopes at different horizons are jointly zero. To compute the statistical significance of the average slope estimate, we conduct Monte Carlo simulations, the details of which are described below.

While the asymptotic $Z$-statistics are consistent, they potentially suffer from small sample biases for the following reasons. First, while the independent variables in the OLS regressions are predetermined they are not necessarily exogenous. This is especially the case when we use valuation

\footnotetext{
${ }^{18}$ The continuously compounded Vwretd and the discretely compounded Vwretd have a correlation of 0.9989 , and our results are robust to using Vwretd.
} 
ratios, since valuation ratios are a function of current price. Stambaugh $(1986,1999)$ shows that in these situations the OLS estimators of the slope coefficients are biased in small samples. Secondly, while the GMM standard errors consistently estimate the asymptotic variance-covariance matrix, Richardson and Smith (1991) show that they are biased in small samples due to the sampling variation in estimating the autocovariances. Lastly, as demonstrated by Richardson and Smith (1991), the asymptotic distribution of the OLS estimators may not be well behaved if $K$ is large relative to $T$, i.e., the degree of overlap is high relative to the sample size.

To account for these issues, we generate finite sample distributions of $Z(b)$ and the average slopes under the null of no predictability and calculate the $p$-values based on their empirical distributions. Monte Carlo experiments require a data-generating process that produces artificial data whose time-series properties are consistent with those in the actual data. Therefore, we generate artificial data using a Vector Autoregression (VAR), and our simulation procedure closely follows Hodrick (1992), Swaminathan (1996) and Lee, Myers, and Swaminathan (1999). Appendix B describes the details of our simulation methodology. ${ }^{19}$

\subsection{Forecasting Regression Results}

In this section we discuss the results from our forecasting regressions involving IRP. We first compare IRP to various valuation ratios, and then compare IRP to a long list of forecasting variables that have been used to predict returns in the literature. Finally, we conduct a variety of robustness checks.

\subsubsection{Regression Results with Valuation Ratios}

Univariate Regression Results In this section, we examine the univariate forecasting power of $I R P$ and other commonly used valuation ratios, by setting $X=I R P, D / P, E / P, B / M$, or $P / Y$ in equation (8). High IRP represents high ex-ante risk premium, and hence we expect high IRP to predict high excess market returns. Prior literature has shown that high valuation ratios $(E / P$, $D / P, B / M)$ predict high stock returns. Boudoukh, Michaely, Richardson, and Roberts (2007) show that Payout Yield $(P / Y)$ is a better forecasting variable than the dividend yield and that it positively predicts future returns. Thus, for all regressions, a one-sided test of the null hypothesis

\footnotetext{
${ }^{19}$ In our reported results below, the variables in the VAR vary with each regression. For example, in the univariate regression of (8) with only one predictive variable in $X_{t}$, the VAR contains two variables, namely, $r_{t}$ and the predictive variable $X_{t}$. In a multivariate regression with two predictive variables in $X_{t}$, the VAR contains three variables, namely, $r_{t}$ and the two predictive variables in $X_{t}$. In unreported results, for predictive variables with the same sample size, we also run a single VAR containing all variables and obtain similar results.
} 
is appropriate.

\section{[INSERT TABLE 2 HERE]}

Panels A-D of Table 2 present univariate regression results for $I R P, D / P, E / P$, and $B / M$, respectively, using monthly data from January 1977 to December 2011. Panel E provides the univariate regression results for $P / Y$, using monthly data from January 1977 to December 2010. Following Boudoukh, Michaely, Richardson, and Roberts (2007), we use the logarithm of P/Y in Panel E.

We observe that as expected, all variables have positive slope coefficients. Because a one-sided test is appropriate, the conventional $5 \%$ critical value is 1.65 . Using this cut-off, IRP is statistically significant at all horizons with the smallest $Z(b)$ being 1.849 at the 1 -month horizon. Among the valuation ratios, only $D / P$ and $P / Y$ have $Z(b)$ larger than 1.65 in any of the horizons. The adjusted $R^{2}$ of IRP is also much larger than that of the valuation ratios: IRP explains $1 \%$ of future market returns at the 1 -month horizon, and $30.5 \%$ at the 4 -year horizon. For all variables, the adjusted $R^{2}$ increases with horizons. As pointed out by Cochrane (2005), the increase in the magnitude of the adjusted $R^{2}$ with forecasting horizon is due to the persistence of the regressors.

However, when judged by simulated $p$-values, $D / P$ is no longer significant, and its simulated $p$-values are all above 0.22 . Since $D / P$ is not statistically significant at any individual horizons, it is not surprising that it is not significant in the joint horizon test either, with a simulated $p$-value for the average slope estimate of just 0.349. This finding is consistent with our discussion in Section 4.1 on the importance of using simulated $p$-values to assess the statistical significance of forecasting variables. That $D / P$ does not predict future market returns is also consistent with recent studies (e.g., Ang and Bekaert (2007); Boudoukh, Richardson, and Whitelaw (2008)).

Unlike the traditional valuation measures, IRP is statistically significant based on both conventional critical values and simulated $p$-values (at the $10 \%$ significance level or better) at all horizons. Not surprisingly, the average slope statistic of 1.748 is highly significant with a simulated $p$-value of 0.020. This suggests that on average, an increase of $1 \%$ in IRP in the current month is associated with an annualized increase of $1.748 \%$ in the excess market return over the next four years which is economically quite significant. Among all the valuation ratios, the payout yield $P / Y$, performs the best in univariate tests with some forecasting power at the 3-year and 4-year forecasting horizons. The average slope, however, is not significant ( $p$-value 0.156). 
Bivariate Regression Results Because $I R P$ is positively correlated with traditional valuation ratios, it is important to know whether IRP still forecasts future market returns in their presence. Given the high correlations among these valuation ratios (see Table 1), to avoid multicollinearity issues, we run bivariate regressions with $I R P$ as one of the regressors and one of the valuation ratios as the other regressor. Based on equation (8), $X$ is one of the following four sets of regressors: $(1)$ $I R P$ and $D / P,(2) I R P$ and $E / P,(3) I R P$ and $B / M$, and (4) IRP and $P / Y$. Again, we expect the slope coefficients of all forecasting variables to be positive, and therefore, one-sided tests of the null of no predictability are appropriate.

\section{[INSERT TABLE 3 HERE]}

Table 3 presents the bivariate regression results. The results in Panels A to D show that IRP continues to strongly predict future returns even in the presence of the other valuation measures. The slope coefficients of $I R P$ are significant at most horizons and the average slope coefficients (in the range of 1.503 to 1.627 ) are all highly significant with simulated $p$-values ranging from 0.043 to 0.051. In contrast, traditional valuation measures have little or no predictive power in the presence of IRP. The slope coefficients are insignificant at all horizons and not surprisingly, the average slope statistics are also insignificant. The results provide strong evidence that IRP is a better predictor of future returns than traditional valuation measures. We next turn to evaluating the forecasting performance of $I R P$ in the presence of (countercyclical) forecasting variables that proxy for the business cycle.

\subsubsection{Regression Results with Business Cycle Variables}

Fama and French (1989) find that business cycle variables such as the default spread and term spread predict stock returns. Given the high positive correlation between IRP and default and term spreads, it is important to determine whether IRP has the ability to forecast future excess returns in the presence of these variables. Ang and Bekaert (2007) show that the short rate negatively predicts future returns at shorter horizons, and while dividend yield does not have predictive power per se, it predicts future market returns in a bivariate regression with the short rate. Therefore, we also examine the predictive power of IRP in the presence of the one-month T-bill rate ( Tbill). Finally, we also control for the 30-year treasury yield (Yield).

Panels F-I of Table 2 presents univariate regression results for Term, Default, Tbill, and Yield. Since Term, Default and Yield move countercyclically with the business cycle, we expect positive 
signs for these variables. For Tbill, we expect a negative sign at shorter horizons. Thus, for these regressions, a one-sided upper or lower tail test of the null hypothesis is appropriate.

The regression results indicate that Term is a strong predictor of future market returns. It has statistically significant predictive power beyond the 2-year horizon based on simulated $p$-values, and the average slope coefficient is also significant ( $p$-value 0.067). Default, however, is not a statistically significant predictor of future returns. Slope coefficients of Tbill and Yield both have the expected signs although none of them are statistically significant.

Panels E-H of Table 3 present the bivariate regression results with $X=($ IRP, Term $),(I R P$, Default), (IRP, Tbill) and (IRP, Yield), respectively. Note that in all these regressions, IRP strongly and positively predicts future market returns. In the presence of Term, IRP is statistically significant at the 1-month and 4-year horizons ( $p$-values 0.009 and 0.039 ), and the average slope statistic is still highly significant ( $p$-value 0.019). Term, on the other hand, is unable to predict future market returns in the presence of IRP. In fact, the slope coefficients corresponding to Term turn negative. Given the high correlation of 0.80 between IRP and Term (see Table 1, Panel B), it appears that the information common to the two variables is being absorbed by IRP. IRP remains highly significant at all horizons in the presence of Default, Tbill or Yield, and its average slope remains highly significant with $p$-values ranging from 0.010 to 0.021 . In contrast, none of these variables is significant in the presence of IRP. The slope coefficients corresponding to Default turn negative while those of Tbill turn positive (Panels F and G). The slope coefficients corresponding to Yield remain mostly positive but only marginally significant at the 4-year horizon. Overall, the results provide strong evidence that the predictive power of $I R P$ is not subsumed by the information in the business cycle variables.

\subsubsection{Regression Results with Other Variables}

We now examine whether IRP forecasts future returns in the presence of several other forecasting variables that have been examined in the literature. The first group of variables includes net equity issuance (ntis), inflation (infl), stock variance (svar), lagged excess market returns (Lagged Vwretd), and the sentiment measure (senti) (January 1977-December 2010); and the second group of variables includes consumption-to-wealth ratio (cay) and investment-to-capital ratio $(i / k)$ (1977.Q1-2008.Q4). Since IRP is obtained every month, we take its quarter-end values as the quarterly IRP.

[INSERT TABLE 4 HERE] 
Baker and Wurgler (2000) show that ntis is a strong predictor of future market returns between 1928 and 1997. In particular, firms issue relatively more equity than debt just before periods of low market returns. So we expect negative coefficients for ntis. Baker and Wurgler (2006) suggest that when sentiment is high, subsequent returns tend to be low, so we expect a negative sign for senti. We should note, however, that the construction of senti uses ex post information which makes it hard to interpret senti as an ex ante forecasting variable. For infl and svar, we expect negative signs. For Lagged Vwretd, we expect a positive sign within a year and a negative sign afterwards. Since we do not have a consistent sign for Lagged Vwretd, the average slope coefficient for Lagged Vwretd is not very informative. We nevertheless report it together with its $p$-value calculated based on the assumption that we expect a positive sign for Lagged Vwretd.

Lettau and Ludvigson (2001) propose cay as a measure of time-varying expected returns with high cay predicting high returns. Since cay also uses ex post information, it is not really an ex ante forecasting variable either. We nevertheless want to know how IRP predicts future returns in its presence. Based on Cochrane (1991), we expect a negative sign for $i / k$.

We run multivariate regressions with $X=(I R P$, ntis, infl $),($ IRP, svar, Lagged Vwretd $),($ IRP, senti), and (IRP, cay, $i / k)$, and the results are provided in Panels A-D of Table 4. The results in Panels A and B show that even after controlling for ntis, infl, svar, and Lagged Vwretd, IRP remains statistically significant at all horizons except the 1-year and 2-year horizons, and the average slopes are highly significant, with $p$-values of 0.014 and 0.013 , respectively. None of the other predictors show any consistent predictive power in the presence of IRP. Panel $\mathrm{C}$ shows that IRP strongly predicts future returns even in the presence of the sentiment measure (which uses ex-post information in its construction). The slope coefficients corresponding to IRP are highly significant at all horizons, and the average slope coefficient is also highly significant ( $p$-value 0.024). The sentiment measure is significant only at the 1-month horizon. Panel D shows that IRP predicts future returns strongly even after controlling for cay and $i / k$. The individual slope coefficients are significant at the 2-year, 3-year, and 4-year horizons and the average slope coefficient is significant at the $10 \%$ level. cay and $i / k$ are not significant in the presence of $I R P$. The superior forecasting power of $I R P$ even in the presence of variables with ex post information is quite impressive. The finding that IRP strongly predicts future returns even in the presence of cay (and other business cycle variables) suggests that IRP may also contain information about aggregate market mispricing. 


\subsubsection{Further Analysis of IRP}

The Role of Growth Forecast Section 2.1 shows that the ICC (and thus IRP) contains information about both dividend yield and future dividend/earnings growth. In this section, we investigate the role of information about future growth rates in the superior forecasting power of $I R P$. Specifically, for each firm, we use $F E_{1} / P$ as an alternative measure of expected return based on the no growth perpetuity valuation model which assumes that earnings do not grow beyond the first year. We then value-weight firm-level $F E_{1} / P$ s to obtain an aggregate $F E_{1} / P$. If growth beyond the first year is an important ingredient of $I R P$, we would expect $I R P$ to outperform $F E_{1} / P$ in predicting future market returns.

\section{[INSERT TABLE 5 HERE]}

Panel A1 of Table 5 provides the univariate regression result of (8) with $X=F E_{1} / P$. We find that $F E_{1} / P$ has a positive sign at all horizons but is not statistically significant at any horizon. Panel A2 provides the bivariate regression of (8) with $X=\left(I R P, F E_{1} / P\right)$. The results show that $I R P$ remains a strong predictor of future returns even in the presence of $F E_{1} / P$. This suggests that the earnings growth forecasts embedded in IRP beyond the first year is important in predicting future returns.

Alternative Model Specifications We conduct a variety of robustness checks in this section. First, we estimate IRP using free cash flow models with finite horizons of $T=10$ and $T=20$ (recall our main approach uses $T=15$ in equation (7)). While the horizons affect the average risk premium (the mean of $I R P$ is $5.32 \%$ for $T=10$ and $8.05 \%$ for $T=20$ ), the regression results are unaffected, both in univariate and in multivariate regressions. Panel B of Table 5 presents the univariate regression results for $I R P$ when they are estimated from $T=10$ and for $T=20$, respectively. In both regressions, $I R P$ is statistically significant in all forecasting horizons, and its slope coefficient across all horizons is also significant ( $p$-value 0.012 if $T=10$, and $p$-value 0.027 if $T=20)$.

Due to difficulty of determining the likelihood of recurrence for repurchases and new equity issues, our main measure of $I R P$ excludes repurchases and new equity issues. As another robustness check, we construct IRP by incorporating repurchases and new equity issues, and provide the univariate regression on this alternative IRP measure (IRP_repurchase) in Panel B of Table 5. IRP_repurchase still positively forecasts future returns and is significant at all horizons, and it is also significant in the joint horizon test ( $p$-value 0.017$)$. 
So far, our measure of implied risk premium is obtained by value-weighting the firm-level $I C C$ s for the $\mathrm{S} \& \mathrm{P} 500$ index firms to obtain the aggregate $I C C$, and then subtracting the one-month T-bill yield from the aggregate $I C C$. We now consider three alternative ways of constructing the implied risk premium. First, we equally-weight the firm-level $I C C$ s for the S\&P 500 firms to obtain the aggregate $I C C$, and then subtract the one-month T-bill yield to construct an equally-weighted implied risk premium measure (IRP_equal). Secondly, rather than use the firms in the S\&P 500 index, we compute the value-weighted $I C C$ using all firms in the sample. The implied risk premium (IRP_all) is then obtained by subtracting the one-month T-bill yield from the aggregate ICC based on all firms. ${ }^{20}$ Finally, we value-weight the firm-level $I C C$ s to obtain the aggregate $I C C$. Rather than subtract the one-month T-bill yield from the aggregate $I C C$, we instead subtract the 30-year treasury yield to obtain the implied risk premium (IRP_yield). Note that in this case, we should ideally use the excess of market returns over 30-year bond returns as the dependent variable. Nevertheless, for comparability, we still use the excess of market returns over T-bill returns as the dependent variable.

Panel B of Table 5 provides the univariate regression results for the three alternative measures of IRP. The results show that all three measures of implied risk premium positively predict future market returns at all forecasting horizons. In particular, IRP_all provides very similar results to $I R P$ : it is significant at every individual horizon as well as in the joint horizon test. IRP_equal is significant at all horizons except the 1-year horizon. IRP_yield has statistical significance at the 1-month and 4-year horizons. The average slope statistic is highly significant for all three measures, with $p$-values being $0.015,0.038$, and 0.033 for IRP_all, IRP_equal, and IRP_yield. In addition to the methodology used in this paper, there are several other procedures used in the literature to compute ICC. Rather than going through all of them, we pick a procedure recommended by Easton (2004) that directly computes the aggregate $I C C$ using a regression approach. Panel B of Table 5 reports results using IRP from this alternate approach. The evidence suggests that this alternate IRP also predicts future returns strongly.

So far, we have used IRP to predict future excess market returns. We now investigate the power of real $I C C$ to predict future real returns, where the real $I C C$ is the difference between the aggregate ICC and the one-month inflation rate (based on CPI for all urban consumers), and the real market returns are the difference between monthly continuously compounded nominal returns and the one-month inflation rate. Panel $\mathrm{B}$ of Table 5 provides the results for real ICC using

\footnotetext{
${ }^{20}$ We also show that our results robust to constructing IRP using the firms in the Dow Jones Industrial Index. These results are available upon request.
} 
monthly data from January 1977 to August 2011. We find that the real ICC is a strong predictor of future real market returns: it is significant at all horizons at the $5 \%$ level, and the average slope has a $p$-value of 0.000 .

Analyst Forecast Optimism Our calculation of IRP uses analysts' forecast of future earnings, which might be biased. Notably, several studies find that analyst forecasts tend to be optimistic. We are interested in time variation in this optimism bias and the role, if any, it might play in the predictive power of IRP. Optimistic analyst forecasts, all else equal, should lead to higher estimates of IRP. In order for analyst optimism to explain our findings, high optimism should predict high returns. We use the growth rate implicit in the $F Y_{2}$ and $F Y_{1}$ forecasts, $g_{2}=F Y_{2} / F Y_{1}-1$ as our measure of time-varying analyst optimism. ${ }^{21}$ If the growth rate is higher than average then analysts are likely to be more optimistic than usual. Note that the time-variation in the implied growth rate could also be due to the business cycle. We are agnostic as to what causes this time-variation and are only interested in examining whether this time-variation adversely affects the predictive power of IRP. For each firm, each month, we compute the implied growth rate $g_{2}$ and then value-weight the firm-level growth rates to obtain the aggregate growth rate. Panel $\mathrm{C} 1$ of Table 5 provides univariate forecasting regression results involving the aggregate implied growth rate. There is a positive relationship between the implied growth rate and future returns although the relationship is insignificant and accompanied by very low $R^{2}$. Panel $\mathrm{C} 2$ provides bivariate results involving $I R P$ and the implied growth rate. The results show that IRP continues to strongly predict future returns with a positive sign even after controlling for the implied growth rate. The coefficients on the implied growth rate, on the other hand, turn negative in the presence of IRP and remain insignificant. These results provide strong evidence that our results are not driven by time-varying analyst optimism.

Alternate Standard Errors Hodrick (1992) develops alternate standard errors for long horizon forecasting regressions that are less biased in small samples than the Newey-West (1987) standard errors and lead to lower type I errors. Our calculation of $Z(b)$ is based on the Newey-West standard errors; however, we draw inferences based on the simulated $p$-values of $Z(b)$, which are obtained by comparing $Z(b)$ to its empirical distributions under the null. Thus, our simulated $p$-values take into account and correct for the small sample bias associated with the Newey-West standard errors. Nevertheless, we conduct a robustness check using the standard errors suggested by Hodrick (1992)

\footnotetext{
${ }^{21}$ We have entertained an alternative definition for forecast optimism using $F E_{1} / E_{0}$, where $E_{0}$ is the realized earning per share in the most recent fiscal year end, and find similar results (available upon request).
} 
to confirm that our results are not sensitive to the choice of standard errors. ${ }^{22}$

When estimating $S_{0}$ in (9), rather than use the Newey-West standard errors which sum up future autocovariance matrices, we adopt the procedure in Hodrick (1992) by summing up $x_{t} x_{t-j}^{\prime}$ into the past:

$$
\widehat{S}_{0}=\frac{1}{T} \sum_{t=K}^{T} \omega k_{t} \omega k_{t}^{\prime},
$$

where

$$
\omega k_{t}=u_{t+1, t}\left(\sum_{i=0}^{K-1} x_{t-i}\right) / K .
$$

\section{[INSERT TABLE 6 HERE]}

Panel A of Table 6 provides the $Z$-statistics based on the Newey-West standard errors $(Z(b))$ and the Hodrick (1992) standard errors $\left(Z(b)^{h d}\right)$, together with their $95 \%$ critical values simulated under the null hypothesis. To save space, we report both statistics only for IRP and $D / P$. Consistent with Hodrick (1992), the magnitudes of $Z(b)^{h d}$ are indeed smaller than those of $Z(b)$ at longer horizons, suggesting that $Z(b)^{h d}$ is more conservative if we use conventional critical values to draw inferences. The $95 \%$ simulated critical values for $Z(b)$ are much larger than the conventional critical value of 1.65 and increase with the forecasting horizon indicating the increasing bias at longer horizons. Although the $95 \%$ simulated critical values for $Z(b)^{h d}$ are also larger than 1.65 , they are smaller than those of $Z(b)$, indicating a smaller bias in $Z(b)^{h d}$.

Panel $\mathrm{B}$ reports univariate regression results for $I R P, D / P, E / P$, and $B / M$ using Hodrick (1992) standard errors to construct the $Z$-statistics, and reports the corresponding simulated $p$ values. The results show that IRP statistically significantly predicts future market returns even using the alternative standard errors and the other valuation ratios do not. For IRP, the simulated $p$-values are smaller than $10 \%$ at all horizons, and the $p$-value of the average slope coefficient is 0.020. In fact, the $p$-values based on $Z(b)^{h d}$ are even smaller than $Z(b)$ in horizons beyond 2 years, which are calculated based on the Newey-West standard errors (Panel A of Table 2). This shows that the predictive power of $I R P$ is very strong, and is not sensitive to the use of a particular standard error.

Panel $\mathrm{C}$ of Table 6 provides the bivariate regression results based on $Z(b)^{h d}$. Consistent with the results reported in Panels A-C of Table 3, while IRP remains statistically significant in the presence of these valuation ratios, none of the other valuation ratios are significant in the presence of $I R P$.

\footnotetext{
${ }^{22}$ In unreported results, we show that our results are also robust to using Hansen and Hodrick (1980) standard errors.
} 


\section{Out-of-Sample Return Predictions}

Recently, evaluating the out-of-sample performance of return prediction variables has received much attention in the literature (see Spiegel (2008) and Welch and Goyal (2008), for more extensive survey of the vast literature on return predictability). Most notably, Welch and Goyal (2008) show that a long list of predictors used in the literature is unable to deliver consistently superior out-of-sample forecasts of the U.S. equity premium relative to a simple forecast based on the historical average. In this section, we evaluate the performance of IRP in out-of-sample forecast tests.

\subsection{Econometric Specification}

We start with the following predictive regression model:

$$
r_{t+1}=\alpha_{i}+\beta_{i} x_{i, t}+\varepsilon_{i, t+1}
$$

where $r_{t+1}$ is the continuously compounded excess return per month defined as the difference between the monthly continuously compounded return on the value-weighted market return including dividends from WRDS and the monthly continuously compounded one-month T-bill rate (i.e., continuously compounded $V$ wretd $), x_{i, t}$ is the $i$ th monthly forecasting variable: $I R P_{t}, D / P_{t}, E / P_{t}$, $B / M_{t}$, Term , Default $_{t}$, Tbill $t$, Yield $_{t}$, and $\varepsilon_{i, t+1}$ is the error term. Following Welch and Goyal (2008), we use a recursive method to estimate the model and generate out-of-sample forecasts of the market returns. Specifically, we divide the entire sample $T$ into two periods: an estimation period composed of the first $m$ observations and an out-of-sample forecast period composed of the remaining $q=T-m$ observations. The initial out-of-sample forecast based on the predictive variable $x_{i, t}$ is generated by

$$
\hat{r}_{i, m+1}=\hat{\alpha}_{i, m}+\hat{\beta}_{i, m} x_{i, m}
$$

where $\hat{\alpha}_{i, m}$ and $\hat{\beta}_{i, m}$ are obtained using ordinary least squares (OLS) by estimating (10) using observations from 1 to $m$. The second out-of-sample forecast is generated according to

$$
\hat{r}_{i, m+2}=\hat{\alpha}_{i, m+1}+\hat{\beta}_{i, m+1} x_{i, m+1},
$$

where $\hat{\alpha}_{i, m+1}$ and $\hat{\beta}_{i, m+1}$ are obtained by estimating (10) using observations from 1 to $m+1$. So when generating the next-period forecast, the forecaster uses all information up to the current period, which mimics the real-time forecasting situation. Proceeding in this manner through the end of the forecast period, for each predictive variable $x_{i}$, we can obtain a time series of predicted market returns $\left\{\hat{r}_{i, t+1}\right\}_{t=m}^{T-1}$. 
Following Campbell and Thompson (2008), Welch and Goyal (2008), and Rapach, Strauss, and Zhou (2010), we use the historical average excess market returns $\bar{r}_{t+1}=\sum_{j=1}^{t} r_{j}$ as a benchmark forecasting model. If the predictive variable $x_{i}$ contains useful information in forecasting future market returns, then $\hat{r}_{i, t+1}$ should be closer to the true market return than $\bar{r}_{t+1}$. We now introduce the forecast evaluation method.

\subsection{Forecast Evaluation}

Following the literature, we compare the performance of alternative predictive variables using the out-of-sample $R^{2}$ statistics, $R_{o s}^{2}$. This is similar to the familiar in-sample $R^{2}$, and is defined as

$$
R_{o s}^{2}=1-\frac{\sum_{k=1}^{q}\left(r_{m+k}-\hat{r}_{i, m+k}\right)^{2}}{\sum_{k=1}^{q}\left(r_{m+k}-\bar{r}_{m+k}\right)^{2}} .
$$

The $R_{o s}^{2}$ statistic measures the reduction in mean squared prediction error (MSPE) for the predictive regression (10) using a particular forecasting variable relative to the historical average forecast. For different predictive variables $x_{i}$, we can obtain different out-of-sample forecast $\hat{r}_{i, m+k}$ and thus different $R_{o s}^{2}$. If a forecast variable beats the historical average forecast, then $R_{o s}^{2}>0$. A predictive variable that has a higher $R_{o s}^{2}$ performs better in the out-of-sample forecasting test.

We formally test whether a predictive regression model using $x_{i}$ has a statistically lower MSPE than the historical average model. This is equivalent to testing the null of $R_{o s}^{2} \leq 0$ against the alternative of $R_{o s}^{2}>0$. Since our approach is equivalent to comparing forecasts from nested models (setting $\beta_{i}=0$ in (10) reduces our predictive regression using $x_{i}$ to the benchmark model using the historical average), we use the adjusted-MSPE statistic of Clark and West (2007): ${ }^{23}$

$$
f_{t+1}=\left(r_{t+1}-\bar{r}_{t+1}\right)^{2}-\left[\left(\left(r_{t+1}-\hat{r}_{i, t+1}\right)^{2}\right)-\left(\left(\bar{r}_{t+1}-\hat{r}_{i, t+1}\right)^{2}\right)\right] .
$$

The adjusted-MSPE $f_{t+1}$ is then regressed on a constant and the $t$-statistic corresponding to the constant is estimated. The $p$-value of $R_{o s}^{2}$ is obtained from the one-sided $t$-statistic (upper-tail) based on the standard normal distribution. ${ }^{24}$

To explicitly account for the risk borne by an investor over the out-of-sample period, we also calculate the realized utility gains for a mean-variance investor (see Marquering and Verbeek (2004); Campbell and Thompson (2008); Welch and Goyal (2008); Wachter and Warusawitharana (2009);

\footnotetext{
${ }^{23}$ The most popular method for testing these kinds of hypotheses is the Diebold and Mariano (1995) and West (1996) statistic, which has a standard normal distribution. However, as pointed out by Clark and McCracken (2001) and McCracken (2007), the Diebold and Mariano (1995) and West (1996) statistic has a nonstandard normal distribution when comparing forecasts from nested models. Hence we use the adjusted statistic.

${ }^{24}$ Clark and West (2007) demonstrate that, in Monte Carlo simulations, this adjusted-MSPE statistic performs reasonably well in terms of size and power when comparing forecasts from nested linear predictive models.
} 
Rapach, Strauss, and Zhou (2010)). More specifically, based on the forecasts of expected return and expected variance of stocks, a mean-variance investor with relative risk aversion parameter $\gamma$ makes her optimal portfolio decision by allocating her portfolio monthly between stocks and risk-free asset. If she forecasts the expected return using historical average, then her allocation to stocks in period $t+1$ is:

$$
w_{1, t}=\left(\frac{1}{\gamma}\right)\left(\frac{\bar{r}_{t+1}}{\hat{\sigma}_{t+1}^{2}}\right)
$$

If she forecasts the expected return using a particular predictive variable, then her allocation to stocks is:

$$
w_{2, t}=\left(\frac{1}{\gamma}\right)\left(\frac{\hat{r}_{i, t+1}}{\hat{\sigma}_{t+1}^{2}}\right) .
$$

In both portfolio decisions, $\hat{\sigma}_{t+1}^{2}$ is the forecast for the variance of stock returns. We estimate $\hat{\sigma}_{t+1}^{2}$ using a ten-year rolling window of monthly returns.

If an investor uses the historical average to make her portfolio decision, her average utility level over the out-of-sample period is:

$$
U_{1}=\mu_{1}-\frac{1}{2} \gamma \hat{\sigma}_{1}^{2}
$$

where $\mu_{1}$ and $\hat{\sigma}_{1}^{2}$ correspond to the sample mean and variance of the return on the portfolio formed based on (11) over the out-of-sample period. The utility level can also be viewed as the certainty equivalent return for the mean-variance investor.

If an investor uses a predictive variable to make her portfolio decision, then her average utility level over the out-of-sample period is:

$$
U_{2}=\mu_{2}-\frac{1}{2} \gamma \hat{\sigma}_{2}^{2}
$$

where $\mu_{2}$ and $\hat{\sigma}_{2}^{2}$ correspond to the sample mean and variance for the return on the portfolio formed based on (12) over the out-of-sample period. ${ }^{25}$

We measure the utility gain of using a particular predictive variable as the difference between (14) and (13). We multiply this difference by 1200 to express it in average annualized percentage return. This utility gain can be viewed as the portfolio management fee that an investor with mean-variance preferences would be willing to pay to access a particular forecasting variable. We report the results based on $\gamma=3$.

In order to explore the information content of $I R P$ relative to other forecasting variables, we also follow Rapach, Strauss, and Zhou (2010) to conduct a forecast encompassing test due to Harvey,

\footnotetext{
${ }^{25}$ Following Campbell and Thompson (2008), we constrain the portfolio weight on stocks to lie between $0 \%$ and $150 \%$ (inclusive) each month.
} 
Leybourne, and Newbold (1998). The null hypothesis is that the model $i$ forecast encompasses the model $j$ forecast against the one-sided alternative that the model $i$ forecast does not encompass the model $j$ forecast. Define $g_{t+1}=\left(\hat{\varepsilon}_{i, t+1}-\hat{\varepsilon}_{j, t+1}\right) \hat{\varepsilon}_{i, t+1}$, where $\hat{\varepsilon}_{i, t+1}\left(\hat{\varepsilon}_{j, t+1}\right)$ is the forecasting error based on predictive variable $i(j)$, i.e, $\hat{\varepsilon}_{i, t+1}=r_{t+1}-\hat{r}_{i, t+1}$, and $\hat{\varepsilon}_{j, t+1}=r_{t+1}-\hat{r}_{j, t+1}$. The Harvey, Leybourne, and Newbold (1998)'s test can be conducted as follows:

$$
H L N=q /(q-1)\left[\hat{V}(\bar{g})^{-1 / 2}\right] \bar{g}
$$

where $\bar{g}=1 / q \sum_{k=1}^{q} g_{t+k}$, and $\hat{V}(\bar{g})=\left(1 / q^{2}\right) \sum_{k=1}^{q}\left(g_{t+k}-\bar{g}\right)^{2}$. The statistical significance of the test statistic is assessed according to the $t_{q-1}$ distribution.

\subsection{Out-of-sample Forecasting Results}

Existing studies of the out-of-sample forecasting performance of predictive variables are mainly conducted at lower frequencies, namely, at annual and quarterly frequencies. Because we construct $I R P$ at the monthly frequency, we evaluate the performance of these variables at a relatively high frequency. We consider two out-of-sample forecast periods: in the first case, the forecast period is from January 1998 to December 2011, and in the second case, the forecast period is from January 2003 to December 2011. The reason for choosing the first forecast period is that existing studies such as Welch and Goyal (2008) and Rapach, Strauss, and Zhou (2010) have shown that many commonly used forecasting variables perform poorly starting in the late 1990s. We chose the second forecasting period to understand how the various forecasting variables performed during the recent housing boom and subsequent financial crisis. In our in-sample analysis, we forecast returns up to four years, and we observe that the predictive power of IRP gets stronger at longer horizons. In the out-of-sample context, since we predict just the next month's return, it is desirable to include predictors from the past and therefore we propose a 2-year moving average of IRP as our out-of-sample forecasting variable. Similarly, we also use a 2-year moving average for valuation ratios such as $D / P, E / P$, and $B / M$.

\section{[INSERT FIGURE 3 HERE]}

Before presenting the test statistics $R_{o s}^{2}$, we first plot the differences between cumulative squared prediction error for the historical average forecast and the cumulative squared prediction error for forecasting models using different predictive variables in Figure 3 for the forecast period of January 1998-December 2011. This figure provides a visual representation of how each model performs over the forecasting period. If a curve lies above the horizontal line at zero, then the forecasting model 
outperforms the historical average model. As pointed out by Welch and Goyal (2008), the units on these plots are not intuitive, what matters is the slope of the curves: a positive slope indicates that a particular forecasting model consistently outperforms the historical average model, while a negative slope indicates the opposite. A forecasting model which consistently beats the historical average model will always have a positive slope. Among the various forecasting variables, IRP performs the best: it stays above zero for most periods and its slope is closest to being always positive. The performance of $D / P, E / P$ and $B / M$ are mixed. The curves stay above zero only some of the times and the slopes are positive only for a relatively short window from the late 1990s to early 2000. The curves of the business cycle variables and interest rates do not even stay above zero.

\section{[INSERT TABLE 7 HERE]}

Panel A of Table 7 reports the $R_{o s}^{2}$ statistics for each of the forecasting variables for the two forecasting periods: January 1998-December 2011 and January 2003-December 2011. In both forecasting periods, IRP produces positive $R_{o s}^{2}$ of $1.22 \%$ and $1.61 \%$, respectively. Campbell and Thompson (2008) argue that even very small positive $R_{o s}^{2}$ values, such as $0.5 \%$ for monthly data, can signal an economically meaningful degree of return predictability for a mean-variance investor, which provides a simple assessment of a variable's forecasting power in practice. On the other hand, valuation ratios $D / P, E / P$, and $B / M$ produce positive $R_{o s}^{2}$ only in the first forecast period $(0.44 \%$, $0.22 \%$, and $0.26 \%$ ), and not in the second period. The business cycle variables yield negative $R_{o s}^{2}$ in both forecast periods, suggesting that these variables cannot beat the simple historical average forecast model. This is consistent with the findings in Welch and Goyal (2008) that valuation ratios and business cycle variables have poor out-of-sample forecasting performances. In contrast, IRP consistently outperforms the historical average in both forecasting periods.

As discussed in Section 5.2, when $R_{o s}^{2}$ is greater than zero, statistical significance can be assessed using the adjusted-MSPE measure in Clark and West (2007). For the variables that produce positive $R_{o s}^{2}$, we obtain the $p$-value of $R_{o s}^{2}$ based on the adjusted-MSPE measure of testing $R_{o s}^{2} \leq 0$ against the alternative of $R_{o s}^{2}>0$. We see that $I R P$ yields statistically significant $R_{o s}^{2}$ in both forecasting periods, while $R_{o s}^{2}$ associated with the valuation ratios in the first forecast period are not significant. These results are consistent with what we observe in Figure 3.

Panel A of Table 7 also reports the utility gains from using a specific forecasting model against the historical average. IRP produces positive utility gains in both forecasting periods, indicating that mean-variance investors should be willing to pay for access to the information in IRP to 
form their optimal portfolios; the utility gain based on IRP is more than $4 \%$ a year. Among other forecasting variables, valuation ratios produce some positive utility gains in the first forecast period; in the second forecast period, only $D / P$ produces positive utility gains. Overall, the economic magnitude of the utility gains for other variables is much smaller than that of IRP.

We now turn to the question of whether IRP brings new information that is not contained in the existing variables. Panel B of Table 7 provides $p$-values corresponding to the Harvey, Leybourne, and Newbold (1998) forecast encompassing test statistic. The $p$-values correspond to an upper tail test of the null hypothesis that the forecast from the row variable $(\mathrm{R})$ encompasses the forecast from the column variable (C) against the alternate that it does not. The results in Panel B of Table 7 show that we cannot reject the null that IRP encompasses the other forecasting variables while we can strongly reject the null that IRP is encompassed by other forecasting variables. This suggests that IRP is more informative than the other forecasting variables in predicting future returns. We also reject the null that valuation ratios are encompassed by Term, Tbill, and Yield in the first forecast period but not in the second forecast period.

\section{Conclusion}

In sum, our results show that IRP is an excellent predictor of future market returns both insample and out-of-sample. In particular, our results provide the first unambiguous evidence of a positive relationship between $I C C$ and future returns. This is especially important for the $I C C$ literature since it validates the usefulness of the ICC approach. Our paper also introduces a new variable to the predictability literature, one that vastly outperforms the existing forecasting variables. The superior performance of $I C C$ should not be surprising since it is computed from a theoretically justifiable valuation model that takes into account future growth rates and makes reasonable economic assumptions in estimating the expected returns of individual stocks. The success of $I C C$ in predicting future returns also has implications for the asset allocation literature which has traditionally relied on dividend-to-price ratio as the key forecasting variable. Now, there is an alternative which directly measures forward-looking expected returns and risk premiums. Finally, our work suggests that the ICC may also be a proxy of aggregate market mispricing since it is able to predict future returns even in the presence of several business cycle proxies. 


\section{Appendices}

\section{Appendix A: Unit Root Test}

In this appendix, we formally test the stationarity of the various variables by conducting PhillipsPerron unit root tests (see Phillips (1987) and Perron (1988)). We run two types of Phillips-Perron unit root tests: regressions with an intercept but without a time-trend, and regressions with both an intercept and a time-trend. The two types of regressions are given below:

Without time trend: $\Delta Y_{t}=a+(c-1) Y_{t-1}+u_{t}$,

With time trend: $\Delta Y_{t}=a+b t+(c-1) Y_{t-1}+u_{t}$.

The null hypothesis in both regressions is that the variable $Y_{t}$ has a unit root; that is, $c=1$. We report the test statistic based on the regression coefficient, $(c-1)$, which allows for serial correlation up to twelve lags in the regression residuals.

Table A1 summarizes the results of the Phillips-Perron unit root tests. We strongly reject the null hypothesis of a unit root for IRP, but not for traditional valuation ratios. This result is consistent with the autocorrelations reported in Panel A of Table 1, i.e., it takes a shorter time for $I R P$ to return to its mean than for $D / P, E / P, B / M$, and $P / Y$.

\section{[INSERT TABLE A1 HERE]}

\section{Appendix B: Monte Carlo Simulation Procedure}

For each regression, we conduct a Monte Carlo simulation using a VAR procedure to assess the statistical significance of relevant statistics. We illustrate our procedure for the bivariate regression involving $I R P$ and $D / P$. The simulation method is conducted in the same way for other regressions.

Define $Z_{t}=\left(r_{t}, I R P_{t}, D / P_{t}\right)^{\prime}$, where $Z_{t}$ is a $3 \times 1$ column vector. We first fit a first-order VAR to $Z_{t}$ using the following specification:

$$
Z_{t+1}=A_{0}+A_{1} Z_{t}+u_{t+1}
$$

where $A_{0}$ is a $3 \times 1$ vector of intercepts and $A_{1}$ is a $3 \times 3$ matrix of VAR coefficients, and $u_{t+1}$ is a $3 \times 1$ vector of VAR residuals. The estimated VAR is used as the data generating process (DGP) for the simulation.

The point estimates in (16) are used to generate artificial data for the Monte Carlo simulations. We impose the null hypothesis of no predictability on $r_{t}$ in the VAR. This is done by setting the slope coefficients on the explanatory variables to zero, and by setting the intercept in the equation of $r_{t}$ to be its unconditional mean. We use the fitted VAR under the null hypothesis of no predictability to generate $T$ observations of the state variable vector, $\left(r_{t}, I R P_{t}, D / P_{t}\right)$. The initial observation for this vector is drawn from a multivariate normal distribution with mean equal to the historical mean and variance-covariance matrix equal to the historical estimated variance-covariance matrix of the vector of state variables. Once the VAR is initiated, shocks for subsequent observations are generated by randomizing (sampling without replacement) among the actual VAR residuals. The VAR residuals for $r_{t}$ are scaled to match its historical standard errors. These artificial data are then used to run bivariate regressions and generate regression statistics. This process is repeated 5, 000 times to obtain empirical distributions of regression statistics. The Matlab numerical recipe mvnrnd is used to generate standard normal random variables. 


\section{References}

Ang, A. and G. Bekaert (2007). Stock return predictability: Is it there? Review of Financial Studies 20(3), pp. 651-707.

Baker, M. and J. Wurgler (2000). The equity share in new issues and aggregate stock returns. Journal of Finance 55(5), pp. 2219-2257.

Baker, M. and J. Wurgler (2006). Investor sentiment and the cross-section of stock returns. Journal of Finance 61(4), pp. 1645-1680.

Barberis, N., M. Huang, and T. Santos (2001). Prospect theory and asset prices. The Quarterly Journal of Economics 116(1), pp. 1-53.

Bekaert, G. and R. J. Hodrick (1992). Characterizing predictable components in excess returns on equity and foreign exchange markets. Journal of Finance 47(2), pp. 467-509.

Botosan, C. A. (1997). Disclosure level and the cost of equity capital. Accounting Review 72 (3), pp. 323-349.

Botosan, C. A. and M. A. Plumlee (2005). Assessing alternative proxies for the expected risk premium. Accounting Review 80(1), pp. 21-53.

Boudoukh, J., R. Michaely, M. Richardson, and M. R. Roberts (2007). On the importance of measuring payout yield: Implications for empirical asset pricing. The Journal of Finance 62(2), pp. 877-915.

Boudoukh, J., M. Richardson, and R. F. Whitelaw (2008). The myth of long-horizon predictability. Review of Financial Studies 21(4), pp. 1577-1605.

Brav, A., R. Lehavy, and R. Michaely (2005). Using expectations to test asset pricing models. Financial Management 34(3), pp. 31-64.

Brennan, M. and A. P. Taylor (2010). Predicting the market using information from equity portfolio returns. Unpublished working paper.

Campbell, J. and R. Shiller (1988). The dividend-price ratio and expectations of future dividends and discount factors. Review of Financial Studies 1(3), pp. 195-228.

Campbell, J. Y. (1987). Stock returns and the term structure. Journal of Financial Economics 18(2), pp. 373-399.

Campbell, J. Y. and J. H. Cochrane (1999). By force of habit: A consumption-based explanation of aggregate stock market behavior. Journal of Political Economy 107(2), pp. 205-251.

Campbell, J. Y., A. W. Lo, and A. C. MacKinlay (1996). The Econometrics of Financial Markets. Princeton University Press.

Campbell, J. Y. and S. B. Thompson (2008). Predicting excess stock returns out of sample: Can anything beat the historical average? Review of Financial Studies 21(4), pp. 1509-1531.

Campbell, J. Y. and T. Vuolteenaho (2004). Inflation illusion and stock prices. American Economic Review $94(2)$, pp. 19-23.

Campbell, J. Y. and M. Yogo (2006). Efficient tests of stock return predictability. Journal of Financial Economics 81(1), pp. 27-60.

Cavanagh, C. L., G. Elliott, and J. H. Stock (1995). Inference in models with nearly integrated regressors. Econometric Theory 11(5), pp. 1131-1147.

Chava, S. and A. Purnanandam (2010). Is Default Risk Negatively Related to Stock Returns? Review of Financial Studies 23(6), 2523-2559.

Chen, L., Z. Da, and X. Zhao (2012). What drives stock price movement? Working paper.

Clark, T. E. and M. W. McCracken (2001). Tests of equal forecast accuracy and encompassing for nested models. Journal of Econometrics 105(1), 85 - 110.

Clark, T. E. and K. D. West (2007). Approximately normal tests for equal predictive accuracy in nested models. Journal of Econometrics 138(1), pp. 291-311.

Claus, J. and J. Thomas (2001). Equity premia as low as three percent? evidence from analysts' earnings forecasts for domestic and international stock markets. Journal of Finance 56(5), pp. 1629-1666.

Cochrane, J. H. (1991). Production-based asset pricing and the link between stock returns and economic fluctuations. Journal of Finance 46(1), pp. 209-237.

Cochrane, J. H. (2005). Asset Pricing. Princeton University Press.

Cochrane, J. H. (2008). The dog that did not bark: A defense of return predictability. Review of Financial Studies 21(4), pp. 1533-1575.

Diebold, F. X. and R. S. Mariano (1995). Comparing predictive accuracy. Journal of Business and Economic Statistics 13(3), pp. 253-263. 
Easton, P. D. (2004). Pe ratios, peg ratios, and estimating the implied expected rate of return on equity capital. Accounting Review 79(1), pp. 73-95.

Easton, P. D. and S. J. Monahan (2005). An evaluation of accounting-based measures of expected returns. Accounting Review 80(2), pp. 501-538.

Fama, E. F. and K. R. French (1988a). Dividend yields and expected stock returns. Journal of Financial Economics 22(1), 3 - 25.

Fama, E. F. and K. R. French (1988b). Permanent and temporary components of stock prices. Journal of Political Economy 96(2), pp. 246-273.

Fama, E. F. and K. R. French (1989). Business conditions and expected returns on stocks and bonds. Journal of Financial Economics 25(1), 23 - 49.

Fama, E. F. and K. R. French (2002). The equity premium. Journal of Finance 57(2), pp. 637-659.

Fama, E. F. and G. W. Schwert (1977). Asset returns and inflation. Journal of Financial Economics 5(2), pp. 115-146.

French, K. R., G. W. Schwert, and R. F. Stambaugh (1987). Expected stock returns and volatility. Journal of Financial Economics 19(1), 3 - 29.

Friend, I., R. Westerfield, and M. Granito (1978). New evidence on the capital asset pricing model. Journal of Finance 33(3), pp. 903-917.

Gebhardt, W. R., C. M. C. Lee, and B. Swaminathan (2001). Toward an implied cost of capital. Journal of Accounting Research 39(1), pp. 135-176.

Gode, D. and P. Mohanram (2003). Inferring the cost of capital using the ohlsonjuettner model. Review of Accounting Studies 8, 399-431.

Goyal, A. and I. Welch (2003). Predicting the equity premium with dividend ratios. Management Science 49(5), pp. 639-654.

Guo, H. (2006). On the out-of-sample predictability of stock market returns. Journal of Business 79(2), pp. 645-670.

Hail, L. and C. Leuz (2006). International differences in the cost of equity capital: Do legal institutions and securities regulation matter? Journal of Accounting Research 44(3), pp. 485-531.

Hansen, L. P. (1982). Large sample properties of generalized method of moments estimators. Econometrica 50(4), pp. 1029-1054.

Harvey, D. I., S. J. Leybourne, and P. Newbold (1998). Tests for forecast encompassing. Journal of Business and Economic Statistics 16(2), pp. 254-259.

Hodrick, R. J. (1992). Dividend yields and expected stock returns: Alternative procedures for inference and measurement. Review of Financial Studies 5(3), pp. 357-386.

Hou, K., M. A. van Dijk, and Y. Zhang (2010). The implied cost of capital: A new approach. Forthcoming, Journal of Accounting and Economics.

Hughes, J., J. Liu, and J. Liu (2009). On the relation between expected returns and implied cost of capital. Review of Accounting Studies 14(2-3), pp. 246-259.

Kaplan, S. N. and R. S. Ruback (1995). The valuation of cash flow forecasts: An empirical analysis. Journal of Finance 50(4), pp. 1059-1093.

Keim, D. B. and R. F. Stambaugh (1986). Predicting returns in the stock and bond markets. Journal of Financial Economics 17(2), pp. 357-390.

Kelly, B. and S. Pruitt (2011). Market expectations in the cross section of present values. Working paper.

Kothari, S. P. and J. Shanken (1997). Book-to-market, dividend yield, and expected market returns: A time-series analysis. Journal of Financial Economics 44(2), pp. 169-203.

Lamont, O. (1998). Earnings and expected returns. The Journal of Finance 53(5), pp. 1563-1587.

Lee, C., D. Ng, and B. Swaminathan (2009). Testing international asset pricing models using implied costs of capital. Journal of Financial and Quantitative Analysis 44(2), pp. 307-335.

Lee, C. M. C., J. Myers, and B. Swaminathan (1999). What is the intrinsic value of the dow? Journal of Finance 54(5), pp. 1693-1741.

Lee, C. M. C., E. C. So, and C. C. Wang (2010). Evaluating implied cost of capital estimates. working paper, Stanford University.

Lettau, M. and S. Ludvigson (2001). Resurrecting the (c)capm: A cross-sectional test when risk premia are time-varying. Journal of Political Economy 109(6), pp. 1238-1287.

Lettau, M. and S. V. Nieuwerburgh (2008). Reconciling the return predictability evidence. Review of Financial Studies 21(4), pp. 1607-1652. 
Lewellen, J. (2004). Predicting returns with financial ratios. Journal of Financial Economics 74(2), pp. 209-235.

Marquering, W. and M. Verbeek (2004). The economic value of predicting stock index returns and volatility. Journal of Financial and Quantitative Analysis 39(2), pp. 407-429.

McCracken, M. W. (2007). Asymptotics for out of sample tests of granger causality. Journal of Econometrics 140 , pp. $719-752$.

Nelson, C. R. (1976). Inflation and rates of return on common stocks. Journal of Finance 31 (2), pp. 471-483.

Nelson, C. R. and M. J. Kim (1993). Predictable stock returns: The role of small sample bias. Journal of Finance 48(2), pp. 641-661.

Newey, W. K. and K. D. West (1987). A simple, positive semi-definite, heteroskedasticity and autocorrelation consistent covariance matrix. Econometrica 55(3), pp. 703-708.

Pastor, L., M. Sinha, and B. Swaminathan (2008). Estimating the intertemporal risk-return tradeoff using the implied cost of capital. Journal of Finance 63(6), pp. 2859-2897.

Perron, P. (1988). Trends and random walks in macroeconomic time series : Further evidence from a new approach. Journal of Economic Dynamics and Control 12(2-3), 297 - 332.

Phillips, P. C. B. (1987). Time series regression with a unit root. Econometrica 55(2), pp. 277-301.

Plumlee, M., C. Botosan, and H. Wen (2011). The relation between expected returns, realized returns, and firm risk characteristics. Forthcoming, Contemporary Accounting Research.

Polk, C., S. Thompson, and T. Vuolteenaho (2006). Cross-sectional forecasts of the equity premium. Journal of Financial Economics 81(1), pp. 101-141.

Pontiff, J. and L. D. Schall (1998). Book-to-market ratios as predictors of market returns. Journal of Financial Economics 49(2), pp. 141-160.

Rapach, D. E., J. K. Strauss, and G. Zhou (2010). Out-of-Sample Equity Premium Prediction: Combination Forecasts and Links to the Real Economy. Review of Financial Studies 23(2), 821-862.

Richardson, M. and T. Smith (1991). Tests of financial models in the presence of overlapping observations. Review of Financial Studies 4(2), pp. 227-254.

Richardson, M. and J. H. Stock (1989). Drawing inferences from statistics based on multiyear asset returns. Journal of Financial Economics 25(2), pp. 323-348.

Richardson, S., I. Tuna, and P. Wysocki (2010). Accounting anomalies and fundamental analysis: A review of recent research advances. Journal of Accounting and Economics 50(2-3), pp. 410-454.

Rytchkov, O. (2008). Filtering out expected dividends and expected returns. Working paper.

Spiegel, M. (2008). Forecasting the equity premium: Where we stand today. Review of Financial Studies 21(4), pp. 1453-1454.

Stambaugh, R. F. (1986). Bias in regressions with lagged stochastic regressors. Working paper, University of Chicago.

Stambaugh, R. F. (1999). Predictive regressions. Journal of Financial Economics 54(3), pp. 375-421.

Swaminathan, B. (1996). Time-varying expected small firm returns and closed-end fund discounts. Review of Financial Studies 9(3), pp. 845-887.

Torous, W., R. Valkanov, and S. Yan (2004). On predicting stock returns with nearly integrated explanatory variables. Journal of Business 77(4), pp. 937-966.

Wachter, J. A. and M. Warusawitharana (2009). Predictable returns and asset allocation: Should a skeptical investor time the market? Journal of Econometrics 148(2), pp. 162-178.

Welch, I. and A. Goyal (2008). A comprehensive look at the empirical performance of equity premium prediction. Review of Financial Studies 21(4), pp. 1455-1508.

West, K. D. (1996). Asymptotic inference about predictive ability. Econometrica 64(5), pp. 1067-1084.

$\mathrm{Wu}$, J. and L. Zhang (2011). Do anomalies exist ex ante? Working Paper. 


\section{Table 1 Summary Statistics for Forecasting Variables}

This table provides summary statistics of forecasting variables used in the paper. The NYSE/AMEX/Nasdaq value-weighted market excess returns ( Vwretd), the implied risk premium (IRP), the dividend-to-price ratio $(D / P)$, the earnings-to-price ratio $(E / P)$, the book-to-market ratio $(B / M)$, the term spread $(T e r m)$, the default spread (Default), the one-month T-bill rate (Tbill), and the 30-year treasury yield (Yield), are monthly data from January 1977 to December 2011; the payout yield $(P / Y)$ (in logarithm), net equity expansion (ntis), inflation (infl), stock variance (svar), lagged excess market returns (Lagged Vwreted), and the sentiment measure (senti) are monthly data from January 1977 to December 2010; the consumption-towealth ratio (cay), and investment-to-capital ratio $(i / k)$ are quarterly data from 1977.Q1 to 2008.Q4. Panel A provides the mean, standard deviation, and autocorrelations for these variables, and Panels B-D provide the pairwise correlations among them, with $p$-values in parentheses. The implied risk premium (IRP) is our new forecasting variable calculated as the difference between the aggregate implied cost of capital and the one-month T-bill yield. All variables except $B / M, P / Y$, svar, senti and cay are reported in annualized percentages. The autocorrelations for Vwretd represent the sum of autocorrelations up to the given lag while the autocorrelations for all other variables represent the autocorrelation at that lag. The detailed description for these variables are provided in Section 3.

\begin{tabular}{ccccccccc}
\hline \multicolumn{7}{c}{ Panel A: Mean, Standard Deviation and Autocorrelations } \\
\cline { 4 - 9 } Variable & Mean & Std. Dev. & 1 & 12 & 24 & 36 & 48 & 60 \\
\hline IRP & 7.07 & 2.68 & 0.95 & 0.56 & 0.10 & -0.20 & -0.25 & -0.09 \\
Vwretd & 6.66 & 15.87 & 0.08 & 0.02 & -0.26 & -0.24 & -0.36 & -0.51 \\
D/P & 2.61 & 1.05 & 0.98 & 0.87 & 0.79 & 0.73 & 0.64 & 0.52 \\
E/P & 6.88 & 2.53 & 0.99 & 0.84 & 0.73 & 0.65 & 0.54 & 0.40 \\
B/M & 0.45 & 0.18 & 0.99 & 0.88 & 0.82 & 0.74 & 0.65 & 0.53 \\
$P / Y$ & -2.26 & 0.25 & 0.98 & 0.71 & 0.57 & 0.39 & 0.37 & 0.29 \\
Term & 3.06 & 1.59 & 0.91 & 0.43 & 0.08 & -0.27 & -0.36 & -0.14 \\
Default & 1.11 & 0.48 & 0.96 & 0.47 & 0.29 & 0.19 & 0.08 & 0.08 \\
Tbill & 5.23 & 3.34 & 0.97 & 0.78 & 0.56 & 0.38 & 0.28 & 0.31 \\
Yield & 7.24 & 2.60 & 0.99 & 0.87 & 0.77 & 0.69 & 0.56 & 0.45 \\
ntis & 16.67 & 11.21 & 0.76 & 0.49 & 0.40 & 0.27 & 0.16 & 0.06 \\
infl & 3.91 & 1.15 & 0.65 & 0.28 & 0.21 & 0.16 & 0.06 & 0.05 \\
svar & 0.26 & 0.54 & 0.46 & 0.03 & -0.01 & -0.01 & -0.03 & 0.00 \\
senti & 0.17 & 0.77 & 0.97 & 0.59 & 0.18 & 0.00 & -0.15 & -0.27 \\
cay & 0.53 & 1.82 & 0.93 & 0.46 & 0.14 & -0.26 & -0.44 & -0.42 \\
i/k & 3.65 & 0.33 & 0.96 & 0.11 & -0.35 & -0.29 & -0.10 & 0.06 \\
\hline
\end{tabular}




\begin{tabular}{|c|c|c|c|c|c|c|c|c|}
\hline \multicolumn{9}{|c|}{ Panel B: Correlation of Monthly Forecasting Variables from 1977.01 to 2011.12} \\
\hline & $I R P$ & $D / P$ & $E / P$ & $B / M$ & Term & Default & Tbill & Yield \\
\hline $\operatorname{IRP}$ & & & & & & & & \\
\hline$D / P$ & $\begin{array}{c}0.26 \\
(0.00)\end{array}$ & & & & & & & \\
\hline$E / P$ & $\begin{array}{c}0.21 \\
(0.00)\end{array}$ & $\begin{array}{c}0.95 \\
(0.00)\end{array}$ & & & & & & \\
\hline$B / M$ & $\begin{array}{c}0.29 \\
(0.00)\end{array}$ & $\begin{array}{c}0.98 \\
(0.00)\end{array}$ & $\begin{array}{c}0.97 \\
(0.00)\end{array}$ & & & & & \\
\hline Term & $\begin{array}{c}0.80 \\
(0.00)\end{array}$ & $\begin{array}{l}-0.15 \\
(0.00)\end{array}$ & $\begin{array}{l}-0.21 \\
(0.00)\end{array}$ & $\begin{array}{l}-0.14 \\
(0.01)\end{array}$ & & & & \\
\hline Default & $\begin{array}{c}0.38 \\
(0.00)\end{array}$ & $\begin{array}{c}0.53 \\
(0.00)\end{array}$ & $\begin{array}{c}0.63 \\
(0.00)\end{array}$ & $\begin{array}{c}0.57 \\
(0.00)\end{array}$ & $\begin{array}{c}0.15 \\
(0.00)\end{array}$ & & & \\
\hline Tbill & $\begin{array}{l}-0.37 \\
(0.00)\end{array}$ & $\begin{array}{c}0.68 \\
(0.00)\end{array}$ & $\begin{array}{c}0.65 \\
(0.00)\end{array}$ & $\begin{array}{c}0.63 \\
(0.00)\end{array}$ & $\begin{array}{l}-0.60 \\
(0.00)\end{array}$ & $\begin{array}{c}0.28 \\
(0.00)\end{array}$ & & \\
\hline Yield & $\begin{array}{c}-0.01 \\
(0.82)\end{array}$ & $\begin{array}{c}0.80 \\
(0.00)\end{array}$ & $\begin{array}{c}0.72 \\
(0.00)\end{array}$ & $\begin{array}{c}0.76 \\
(0.00) \\
\end{array}$ & $\begin{array}{l}-0.23 \\
(0.00)\end{array}$ & $\begin{array}{c}0.38 \\
(0.00) \\
\end{array}$ & $\begin{array}{c}0.87 \\
(0.00)\end{array}$ & \\
\hline
\end{tabular}

Panel C: Correlation of Monthly Forecasting Variables from 1977.01 to 2010.12

\begin{tabular}{|c|c|c|c|c|c|c|c|}
\hline & $I R P$ & $P / Y$ & ntis & infl & svar & Lagged Vwretd & senti \\
\hline$I R P$ & & & & & & & \\
\hline$P / Y$ & $\begin{array}{c}0.38 \\
(0.00)\end{array}$ & & & & & & \\
\hline ntis & $\begin{array}{c}0.17 \\
(0.00)\end{array}$ & $\begin{array}{c}0.34 \\
(0.00)\end{array}$ & & & & & \\
\hline infl & $\begin{array}{l}-0.24 \\
(0.00)\end{array}$ & $\begin{array}{c}0.24 \\
(0.00)\end{array}$ & $\begin{array}{c}0.19 \\
(0.00)\end{array}$ & & & & \\
\hline svar & $\begin{array}{c}0.16 \\
(0.00)\end{array}$ & $\begin{array}{l}-0.04 \\
(0.43)\end{array}$ & $\begin{array}{c}0.07 \\
(0.18)\end{array}$ & $\begin{array}{l}-0.31 \\
(0.00)\end{array}$ & & & \\
\hline Lagged Vwretd & $\begin{array}{c}0.02 \\
(0.76)\end{array}$ & $\begin{array}{c}0.04 \\
(0.38)\end{array}$ & $\begin{array}{l}-0.09 \\
(0.06)\end{array}$ & $\begin{array}{c}0.07 \\
(0.14)\end{array}$ & $\begin{array}{l}-0.37 \\
(0.00)\end{array}$ & & \\
\hline senti & $\begin{array}{c}-0.06 \\
(0.26)\end{array}$ & $\begin{array}{l}-0.16 \\
(0.00)\end{array}$ & $\begin{array}{c}0.28 \\
(0.00)\end{array}$ & $\begin{array}{l}-0.12 \\
(0.01)\end{array}$ & $\begin{array}{c}0.03 \\
(0.48)\end{array}$ & $\begin{array}{l}-0.07 \\
(0.15)\end{array}$ & \\
\hline
\end{tabular}

Panel D: Correlation of Quarterly Forecasting Variables from 1977.Q1 to 2008.Q4

\begin{tabular}{cccc}
\hline & IRP & cay & $i / k$ \\
\hline IRP & & & \\
cay & 0.12 & & \\
& $(0.19)$ & & \\
$i / k$ & -0.66 & -0.11 \\
& $(0.00)$ & $(0.22)$ \\
\hline
\end{tabular}




\section{Table 2 Univariate Regressions for IRP, Valuation Ratios, and Business Cycle Variables}

This table summarizes univariate forecasting regression results in equation (8). The dependent variable in these regressions is the average monthly continuously compounded excess returns defined as the difference between the average monthly continuously compounded value-weighted market return including dividends from WRDS and the average monthly continuously compounded one-month T-bill return. The independent variables are the implied risk premium $(I R P)$, the dividend-to-price ratio $(D / P)$, the earnings-to-price ratio $(E / P)$, the book-to-market ratio $(B / M)$, the payout yield $(P / Y)$, the term spread $(T e r m)$, the default spread (Default), the one-month T-bill rate (Tbill), and the 30-year treasury yield (Yield), in Panels A-I, respectively. $P / Y$ is in logarithm form and spans January 1977 to December 2010. All other variables span January 1977 to December 2011. Since our dependent variable is average monthly excess returns, we divide IRP, D/P, E/P, B/M, Term, Default, Tbill, and Yield also by 12 . This rescaling is done simply to ensure that the magnitude of slope coefficients is not too small and does not affect their statistical significance. In forecasting horizons beyond one-month, the regressions use overlapping observations. $b$ is the slope coefficient from the OLS regressions. avg. is the average slope coefficient. $Z(b)$ is the asymptotic $Z$-statistics computed using the GMM standard errors with $K-1$ Newey-West lag correction. These standard errors correct for the autocorrelation in regressions due to overlapping observations and for generalized conditional heteroskedasticity. The $a d j . R^{2}$ is obtained from the OLS regression. The $p$-values of $Z$-statistics and the average slope coefficient are obtained by comparing the test statistics with their empirical distribution generated under the null of no predictability from 5,000 trials of a Monte Carlo simulation. The artificial data for the simulation are generated under the null using the VAR approach described in Appendix B.

\begin{tabular}{|c|c|c|c|c|c|c|c|c|c|c|c|c|}
\hline \multirow[b]{2}{*}{$K$} & \multicolumn{4}{|c|}{ Panel A: IRP } & \multicolumn{4}{|c|}{ Panel B: $D / P$} & \multicolumn{4}{|c|}{ Panel C: $E / P$} \\
\hline & $b$ & $Z(b)$ & pval & adj.R $R^{2}$ & $b$ & $Z(b)$ & pval & $\operatorname{adj.R^{2}}$ & $b$ & $Z(b)$ & pval & $\operatorname{adj.} R^{2}$ \\
\hline 1 & 2.023 & 1.849 & 0.052 & 0.009 & 3.423 & 1.298 & 0.221 & 0.004 & 1.196 & 1.058 & 0.320 & 0.003 \\
\hline 12 & 1.627 & 2.295 & 0.076 & 0.066 & 3.424 & 1.594 & 0.271 & 0.046 & 1.131 & 1.281 & 0.359 & 0.030 \\
\hline 24 & 1.772 & 2.522 & 0.079 & 0.173 & 2.744 & 1.384 & 0.352 & 0.070 & 0.890 & 1.125 & 0.440 & 0.043 \\
\hline 36 & 1.773 & 3.175 & 0.048 & 0.267 & 2.247 & 1.421 & 0.379 & 0.084 & 0.709 & 1.052 & 0.491 & 0.048 \\
\hline 48 & 1.546 & 3.900 & 0.035 & 0.305 & 2.236 & 1.875 & 0.316 & 0.128 & 0.664 & 1.225 & 0.481 & 0.066 \\
\hline avg. & 1.748 & & 0.020 & & 2.815 & & 0.349 & & 0.918 & & 0.441 & \\
\hline
\end{tabular}

\begin{tabular}{|c|c|c|c|c|c|c|c|c|c|c|c|c|}
\hline \multirow[b]{2}{*}{$K$} & \multicolumn{4}{|c|}{ Panel D: $B / M$} & \multicolumn{4}{|c|}{ Panel E: $P / Y$} & \multicolumn{4}{|c|}{ Panel F: Term } \\
\hline & $b$ & $Z(b)$ & pval & adj.R $R^{2}$ & $b$ & $Z(b)$ & pval & $\operatorname{adj} . R^{2}$ & $b$ & $Z(b)$ & pval & adj.R $R^{2}$ \\
\hline 1 & 0.158 & 1.036 & 0.365 & 0.003 & 0.787 & 0.752 & 0.245 & 0.002 & 0.958 & 0.534 & 0.312 & 0.001 \\
\hline 12 & 0.169 & 1.395 & 0.365 & 0.034 & 1.127 & 1.417 & 0.161 & 0.042 & 1.792 & 1.532 & 0.129 & 0.029 \\
\hline 24 & 0.130 & 1.174 & 0.470 & 0.048 & 1.183 & 1.847 & 0.119 & 0.113 & 2.170 & 2.364 & 0.056 & 0.095 \\
\hline 36 & 0.112 & 1.178 & 0.499 & 0.062 & 0.964 & 2.328 & 0.089 & 0.125 & 2.069 & 3.171 & 0.019 & 0.144 \\
\hline 48 & 0.103 & 1.374 & 0.485 & 0.081 & 0.863 & 2.991 & 0.064 & 0.160 & 1.644 & 3.008 & 0.037 & 0.137 \\
\hline \multirow[t]{2}{*}{ avg. } & 0.134 & & 0.519 & & 0.985 & & 0.156 & & 1.726 & & 0.067 & \\
\hline & \multicolumn{4}{|c|}{ Panel G: Default } & \multicolumn{4}{|c|}{ Panel H: Tbill } & \multicolumn{4}{|c|}{ Panel I: Yield } \\
\hline$K$ & $b$ & $Z(b)$ & pval & $\overline{a d j . R^{2}}$ & $b$ & $Z(b)$ & pval & $\overline{a d j .} R^{2}$ & $b$ & $Z(b)$ & pval & $\operatorname{adj} \cdot R^{2}$ \\
\hline 1 & -2.292 & -0.289 & 0.683 & 0.000 & -0.394 & -0.456 & 0.308 & 0.001 & -0.248 & -0.217 & 0.589 & 0.000 \\
\hline 12 & 3.586 & 0.799 & 0.357 & 0.011 & -0.275 & -0.373 & 0.362 & 0.003 & 0.398 & 0.383 & 0.385 & 0.004 \\
\hline 24 & 2.580 & 0.731 & 0.385 & 0.013 & -0.237 & -0.697 & 0.288 & 0.005 & 0.645 & 0.920 & 0.262 & 0.022 \\
\hline 36 & 1.674 & 0.537 & 0.453 & 0.009 & -0.066 & -0.204 & 0.429 & 0.001 & 0.822 & 1.464 & 0.180 & 0.059 \\
\hline 48 & 2.411 & 0.723 & 0.428 & 0.022 & 0.128 & 0.393 & 0.577 & 0.003 & 0.893 & 1.975 & 0.132 & 0.103 \\
\hline avg. & 1.592 & & 0.470 & & -0.169 & & 0.380 & & 0.502 & & 0.354 & \\
\hline
\end{tabular}




\section{Table 3 Bivariate Regressions Involving IRP, Valuation Ratios, and Business Cycle Variables}

This table summarizes bivariate forecasting regression results in equation (8). The independent variables are the implied risk premium $(I R P)$ and dividend-to-price ratio $(D / P)$ in Panel $\mathrm{A}, I R P$ and earnings-to-price ratio $(E / P)$ in Panel $\mathrm{B}, I R P$ and book-to-market ratio $(B / M)$ in Panel $\mathrm{C}, I R P$ and the payout yield $(P / Y)$ in Panel D, IRP and the term spread (Term) in Panel E, IRP and the default spread (Default) in Panel F, IRP and the one-month T-bill rate (Tbill) in Panel G, and IRP and the 30-year treasury yield (Yield) in Panel H. The dependent variable in these regressions is the continuously compounded excess return per month defined as the difference between the monthly continuously compounded return on the value-weighted market return including dividends from WRDS and the monthly continuously compounded one-month T-bill rate. $P / Y$ is in logarithm form and spans January 1977 to December 2010. All other variables span January 1977 to December 2011. Since our dependent variable is average monthly excess returns, we divide $I R P, D / P$, $E / P, B / M, T e r m$, Default, Tbill, and Yield also by 12 . This rescaling does not affect the significance of the slopes. $K$ is the forecasting horizon in months. In forecasting horizons beyond one-month, the regressions use overlapping observations. $b$ and $c$ are the slope coefficients from the OLS regressions. avg. is the average slope coefficient. $Z(b)$ and $Z(c)$ are the asymptotic $Z$-statistics computed using the GMM standard errors with $K-1$ Newey-West lag correction. These standard errors correct for the autocorrelation in regressions due to overlapping observations and for generalized conditional heteroskedasticity. The $a d j . R^{2}$ is obtained from the OLS regression. The $p$-values of $Z$-statistics and the average slope coefficient are obtained by comparing the test statistics with their empirical distribution generated under the null of no predictability from 5,000 trials of a Monte Carlo simulation. The artificial data for the simulation are generated under the null using the VAR approach described in Appendix B.

\begin{tabular}{|c|c|c|c|c|c|c|c|}
\hline \multicolumn{8}{|c|}{ Panel A: Bivariate Regression Involving $I R P$ and $D / P$} \\
\hline & \multicolumn{3}{|c|}{$I R P$} & \multicolumn{3}{|c|}{$D / P$} & \multirow[b]{2}{*}{$\operatorname{adj.} R^{2}$} \\
\hline$K$ & $b$ & $Z(b)$ & pval & $c$ & $Z(c)$ & pval & \\
\hline 1 & 1.794 & 1.584 & 0.100 & 2.236 & 0.824 & 0.325 & 0.006 \\
\hline 12 & 1.348 & 1.878 & 0.135 & 2.455 & 1.180 & 0.304 & 0.084 \\
\hline 24 & 1.571 & 2.834 & 0.058 & 1.523 & 1.079 & 0.357 & 0.188 \\
\hline 36 & 1.623 & 3.501 & 0.041 & 1.007 & 1.023 & 0.393 & 0.278 \\
\hline 48 & 1.362 & 3.998 & 0.032 & 1.163 & 1.513 & 0.312 & 0.332 \\
\hline avg. & 1.539 & & 0.045 & 1.677 & & 0.416 & \\
\hline \multicolumn{8}{|c|}{ Panel B: Bivariate Regression Involving $I R P$ and $E / P$} \\
\hline & \multicolumn{3}{|c|}{$I R P$} & \multicolumn{3}{|c|}{$E / P$} & \\
\hline$K$ & $b$ & $Z(b)$ & pval & $c$ & $Z(c)$ & pval & $\operatorname{adj} . R^{2}$ \\
\hline 1 & 1.870 & 1.703 & 0.085 & 0.789 & 0.703 & 0.381 & 0.006 \\
\hline 12 & 1.462 & 2.084 & 0.112 & 0.806 & 1.008 & 0.369 & 0.076 \\
\hline 24 & 1.655 & 2.753 & 0.071 & 0.500 & 0.950 & 0.400 & 0.181 \\
\hline 36 & 1.689 & 3.495 & 0.044 & 0.349 & 0.890 & 0.433 & 0.274 \\
\hline 48 & 1.459 & 4.167 & 0.034 & 0.365 & 1.172 & 0.391 & 0.320 \\
\hline avg. & 1.627 & & 0.043 & 0.562 & & 0.478 & \\
\hline \multicolumn{8}{|c|}{ Panel C: Bivariate Regression Involving $I R P$ and $B / M$} \\
\hline & \multicolumn{3}{|c|}{$I R P$} & \multicolumn{3}{|c|}{$B / M$} & \\
\hline$K$ & $b$ & $Z(b)$ & pval & $c$ & $Z(c)$ & pval & $\operatorname{adj} . R^{2}$ \\
\hline 1 & 1.870 & 1.655 & 0.089 & 0.079 & 0.506 & 0.510 & 0.005 \\
\hline 12 & 1.407 & 1.985 & 0.126 & 0.109 & 0.941 & 0.424 & 0.075 \\
\hline 24 & 1.641 & 2.870 & 0.060 & 0.059 & 0.760 & 0.489 & 0.177 \\
\hline 36 & 1.673 & 3.578 & 0.038 & 0.039 & 0.655 & 0.532 & 0.270 \\
\hline 48 & 1.441 & 3.914 & 0.035 & 0.040 & 0.792 & 0.517 & 0.312 \\
\hline avg. & 1.607 & & 0.048 & 0.065 & & 0.563 & \\
\hline
\end{tabular}




\begin{tabular}{|c|c|c|c|c|c|c|c|}
\hline \multicolumn{8}{|c|}{ Panel D: Bivariate Regression Involving $I R P$ and $P / Y$} \\
\hline \multirow[b]{2}{*}{$K$} & \multicolumn{3}{|c|}{$\operatorname{IRP}$} & \multicolumn{3}{|c|}{$P / Y$} & \multirow[b]{2}{*}{$\operatorname{adj} . R^{2}$} \\
\hline & $b$ & $Z(b)$ & pval & $c$ & $Z(c)$ & pval & \\
\hline 1 & 2.164 & 1.879 & 0.053 & 0.060 & 0.055 & 0.513 & 0.006 \\
\hline 12 & 1.220 & 1.821 & 0.139 & 0.680 & 0.851 & 0.297 & 0.065 \\
\hline 24 & 1.264 & 2.083 & 0.130 & 0.726 & 1.229 & 0.238 & 0.173 \\
\hline 36 & 1.587 & 3.163 & 0.057 & 0.408 & 1.292 & 0.243 & 0.288 \\
\hline 48 & 1.279 & 3.452 & 0.056 & 0.411 & 1.766 & 0.186 & 0.323 \\
\hline avg. & 1.503 & & 0.051 & 0.457 & & 0.344 & \\
\hline \multicolumn{8}{|c|}{ Panel E: Bivariate Regression Involving IRP and Term } \\
\hline & \multicolumn{3}{|c|}{$I R P$} & \multicolumn{3}{|c|}{ Term } & \\
\hline$K$ & $b$ & $Z(b)$ & pval & $c$ & $Z(c)$ & pval & $\operatorname{adj} . R^{2}$ \\
\hline 1 & 4.443 & 2.515 & 0.009 & -5.060 & -1.783 & 0.951 & 0.012 \\
\hline 12 & 2.154 & 1.659 & 0.158 & -1.102 & -0.529 & 0.632 & 0.066 \\
\hline 24 & 1.964 & 1.598 & 0.197 & -0.398 & -0.251 & 0.543 & 0.170 \\
\hline 36 & 1.927 & 2.051 & 0.141 & -0.313 & -0.268 & 0.544 & 0.264 \\
\hline 48 & 1.846 & 3.473 & 0.039 & -0.617 & -1.058 & 0.744 & 0.309 \\
\hline avg. & 2.467 & & 0.019 & -1.498 & & 0.801 & \\
\hline \multicolumn{8}{|c|}{ Panel F: Bivariate Regression Involving IRP and Default } \\
\hline & \multicolumn{3}{|c|}{$I R P$} & \multicolumn{3}{|c|}{ Default } & \\
\hline$K$ & $b$ & $Z(b)$ & pval & $c$ & $Z(c)$ & pval & $\operatorname{adj.} R^{2}$ \\
\hline 1 & 2.540 & 2.368 & 0.013 & -7.622 & -0.967 & 0.837 & 0.008 \\
\hline 12 & 1.618 & 2.179 & 0.086 & 0.128 & 0.030 & 0.494 & 0.062 \\
\hline 24 & 1.883 & 2.814 & 0.053 & -1.451 & -0.536 & 0.643 & 0.172 \\
\hline 36 & 1.917 & 3.417 & 0.038 & -2.063 & -0.834 & 0.707 & 0.274 \\
\hline 48 & 1.583 & 3.582 & 0.040 & -0.643 & -0.231 & 0.563 & 0.303 \\
\hline avg. & 1.908 & & 0.010 & -2.330 & & 0.698 & \\
\hline \multicolumn{8}{|c|}{ Panel G: Bivariate Regression Involving IRP and Tbill } \\
\hline & \multicolumn{3}{|c|}{$\operatorname{IRP}$} & \multicolumn{3}{|c|}{ Tbill } & \\
\hline$K$ & $b$ & $Z(b)$ & pval & $c$ & $Z(c)$ & pval & $\operatorname{adj} . R^{2}$ \\
\hline 1 & 2.135 & 1.896 & 0.043 & 0.243 & 0.277 & 0.646 & 0.005 \\
\hline 12 & 1.712 & 2.191 & 0.076 & 0.203 & 0.273 & 0.623 & 0.063 \\
\hline 24 & 1.841 & 2.320 & 0.085 & 0.197 & 0.555 & 0.699 & 0.171 \\
\hline 36 & 1.831 & 3.083 & 0.044 & 0.229 & 0.867 & 0.758 & 0.270 \\
\hline 48 & 1.617 & 4.001 & 0.020 & 0.346 & 1.501 & 0.856 & 0.324 \\
\hline avg. & 1.827 & & 0.010 & 0.244 & & 0.698 & \\
\hline \multicolumn{8}{|c|}{ Panel H: Bivariate Regression Involving IRP and Yield } \\
\hline & \multicolumn{3}{|c|}{$I R P$} & \multicolumn{3}{|c|}{ Yield } & \\
\hline$K$ & $b$ & $Z(b)$ & pval & $c$ & $Z(c)$ & pval & $\operatorname{adj} . R^{2}$ \\
\hline 1 & 2.021 & 1.850 & 0.052 & -0.233 & -0.206 & 0.482 & 0.005 \\
\hline 12 & 1.617 & 2.251 & 0.082 & 0.344 & 0.367 & 0.312 & 0.064 \\
\hline 24 & 1.727 & 2.556 & 0.078 & 0.472 & 0.909 & 0.201 & 0.180 \\
\hline 36 & 1.673 & 3.224 & 0.056 & 0.491 & 1.364 & 0.145 & 0.283 \\
\hline 48 & 1.409 & 3.798 & 0.039 & 0.533 & 1.747 & 0.118 & 0.336 \\
\hline avg. & 1.689 & & 0.021 & 0.321 & & 0.302 & \\
\hline
\end{tabular}




\section{Table 4 Multivariate Regressions with Other Forecasting Variables}

This table provides multivariate regression results of equation (8). The independent variables are IRP, ntis, and infl in Panel A, IRP, svar, and Lagged Vwretd in Panel B, IRP and senti in Panel C, and quarterly IRP, $c a y$, and $i / k$ in Panel D. Panels A-C use monthly data from January 1977 to December 2010, and Panel D uses quarterly data from 1977.Q1 to 2008.Q4. The quarterly IRP is the quarter-end monthly IRP. The dependent variable in these regressions is the continuously compounded excess return per month (per quarter) defined as the difference between the monthly (quarterly) continuously compounded return on the value-weighted market return including dividends from WRDS and the monthly (quarterly) continuously compounded onemonth T-bill rate. $K$ is the forecasting horizon in months (quarters) for monthly (quarterly) regressions. In forecasting horizons beyond one-month (one-quarter), the regressions use overlapping observations. $b$, $c$, and $d$ are the slope coefficients from the OLS regressions. avg. is the average slope coefficient. $Z(b)$, $Z(c)$, and $Z(d)$ are the asymptotic $Z$-statistics computed using the GMM standard errors with $K-1$ Newey-West lag correction. These standard errors correct for the autocorrelation in regressions due to overlapping observations and for generalized conditional heteroskedasticity. The $a d j . R^{2}$ is obtained from the OLS regression. The $p$-values of $Z$-statistics and the average slope coefficient are obtained by comparing the test statistics with their empirical distribution generated under the null of no predictability from 5,000 trials of a Monte Carlo simulation. The artificial data for the simulation are generated under the null using the VAR approach described in Appendix B.

\begin{tabular}{|c|c|c|c|c|c|c|c|c|c|c|}
\hline \multirow{3}{*}{$K$} & \multirow{2}{*}{\multicolumn{3}{|c|}{$\operatorname{IRP}$}} & \multirow{2}{*}{\multicolumn{3}{|c|}{ ntis }} & \multirow{2}{*}{\multicolumn{3}{|c|}{ infl }} & \multirow{3}{*}{$\operatorname{adj} . R^{2}$} \\
\hline & & & & & & & & & & \\
\hline & $b$ & $Z(b)$ & pval & $c$ & $Z(c)$ & pval & $d$ & $Z(d)$ & pval & \\
\hline 1 & 2.787 & 2.457 & 0.012 & -0.062 & -2.341 & 0.011 & 0.162 & 0.158 & 0.621 & 0.025 \\
\hline 12 & 1.675 & 2.143 & 0.091 & -0.019 & -1.666 & 0.104 & -0.197 & -0.516 & 0.471 & 0.080 \\
\hline 24 & 1.683 & 2.012 & 0.129 & -0.003 & -0.407 & 0.398 & -0.075 & -0.282 & 0.600 & 0.140 \\
\hline 36 & 1.832 & 2.955 & 0.062 & 0.000 & -0.019 & 0.524 & 0.044 & 0.186 & 0.759 & 0.268 \\
\hline 48 & 1.520 & 3.669 & 0.042 & 0.003 & 0.579 & 0.693 & 0.063 & 0.434 & 0.834 & 0.297 \\
\hline avg. & 1.899 & & 0.014 & -0.016 & & 0.041 & -0.001 & & 0.619 & \\
\hline
\end{tabular}

Panel B: Multivariate Regression Involving IRP, svar and Lagged Vwretd

\begin{tabular}{|c|c|c|c|c|c|c|c|c|c|c|}
\hline \multirow[b]{2}{*}{$K$} & \multicolumn{3}{|c|}{$I R P$} & \multicolumn{3}{|c|}{ svar } & \multicolumn{3}{|c|}{ Lagged Vwretd } & \multirow[b]{2}{*}{$\operatorname{adj} \cdot R^{2}$} \\
\hline & $b$ & $Z(b)$ & pval & $c$ & $Z(c)$ & pval & $d$ & $Z(d)$ & pval & \\
\hline 1 & 2.622 & 2.408 & 0.015 & -1.107 & -2.169 & 0.030 & 0.049 & 0.860 & 0.173 & 0.027 \\
\hline 12 & 1.534 & 1.989 & 0.104 & 0.074 & 0.497 & 0.620 & 0.010 & 0.604 & 0.185 & 0.052 \\
\hline 24 & 1.695 & 2.155 & 0.111 & -0.061 & -0.629 & 0.299 & -0.011 & -0.983 & 0.655 & 0.140 \\
\hline 36 & 1.843 & 3.270 & 0.041 & -0.227 & -2.395 & 0.055 & -0.013 & -2.122 & 0.862 & 0.284 \\
\hline 48 & 1.538 & 3.858 & 0.033 & -0.155 & -1.393 & 0.160 & -0.013 & -2.736 & 0.906 & 0.307 \\
\hline avg. & 1.846 & & 0.013 & -0.295 & & 0.021 & 0.004 & & 0.266 & \\
\hline
\end{tabular}

Panel C: Bivariate Regression Involving IRP and senti

\begin{tabular}{|c|c|c|c|c|c|c|c|}
\hline \multirow[b]{2}{*}{$K$} & \multicolumn{3}{|c|}{ IRP } & \multicolumn{3}{|c|}{ senti } & \multirow[b]{2}{*}{$\operatorname{adj} . R^{2}$} \\
\hline & $b$ & $Z(b)$ & pval & $c$ & $Z(c)$ & pval & \\
\hline 1 & 2.110 & 1.905 & 0.049 & -0.425 & -1.453 & 0.098 & 0.011 \\
\hline 12 & 1.518 & 2.136 & 0.088 & -0.337 & -1.555 & 0.157 & 0.088 \\
\hline 24 & 1.677 & 2.357 & 0.093 & -0.206 & -1.346 & 0.256 & 0.171 \\
\hline 36 & 1.818 & 3.268 & 0.051 & -0.061 & -0.920 & 0.414 & 0.275 \\
\hline 48 & 1.522 & 3.742 & 0.042 & -0.014 & -0.235 & 0.643 & 0.294 \\
\hline avg. & 1.729 & & 0.024 & -0.209 & & 0.302 & \\
\hline
\end{tabular}

Panel D: Multivariate Regression Involving Quarterly $I R P$, cay and $i / k$

\begin{tabular}{|c|c|c|c|c|c|c|c|c|c|c|}
\hline \multirow[b]{2}{*}{$K$} & \multicolumn{3}{|c|}{$I R P$} & \multicolumn{3}{|c|}{ cay } & \multicolumn{3}{|c|}{$i / k$} & \multirow[b]{2}{*}{$\operatorname{adj.} R^{2}$} \\
\hline & $b$ & $Z(b)$ & pval & $c$ & $Z(c)$ & pval & $d$ & $Z(d)$ & pval & \\
\hline 1 & 4.532 & 0.849 & 0.272 & 0.717 & 2.173 & 0.049 & 0.829 & 0.279 & 0.634 & 0.012 \\
\hline 4 & 5.306 & 1.769 & 0.130 & 0.534 & 1.939 & 0.161 & 1.076 & 0.611 & 0.713 & 0.091 \\
\hline 8 & 4.320 & 2.866 & 0.043 & 0.477 & 2.200 & 0.161 & -0.161 & -0.102 & 0.513 & 0.235 \\
\hline 12 & 3.605 & 4.535 & 0.007 & 0.505 & 2.446 & 0.163 & -0.966 & -0.829 & 0.350 & 0.403 \\
\hline 16 & 3.186 & 5.055 & 0.006 & 0.487 & 3.157 & 0.123 & -0.942 & -1.031 & 0.333 & 0.523 \\
\hline avg. & 4.190 & & 0.100 & 0.544 & & 0.170 & -0.033 & & 0.534 & \\
\hline
\end{tabular}




\section{Table 5 Growth Forecast, Alternative IRP Specifications and Analysts' Forecast Optimism}

This table provides a variety of analysis discussed in Section 4.2.4. Panel A analyzes the role of the dividend growth component of $I R P$ in forecasting future market returns. $F E_{1} / P$ is the expected return which does not incorporate forecasts of future dividend growth. Panel A1 provides the univariate regression of $F E_{1} / P$, and Panel A2 provides the bivariate regression of $I R P$ and $F E_{1} / P$. Panel B provides univariate regression of (8) for alternative measures of IRP. It first provides the results for three alternative measures of IRP which are obtained with forecasting horizon $T=10, T=20$, and incorporating share repurchases and new stock issues, respectively. It also provides the results for three alternative measures of IRP: IRP_equal, IRP_all, and IRP_yield, where IRP_equal is the equally-weighted average of the firm-level IRP for firms in the S\&P 500 index; IRP_all is the value-weighted average of the firm-level IRP for all firms in our sample universe, and IRP_yield is the value-weighted average of the firm-level IRP for firms in the S\&P 500 index, but the firm-level IRP is calculated by subtracting the 30-year treasury yield from the firm-level ICC. Panel B also provides the regression results for IRP where $I C C$ is calculated based on Easton (2004)'s method. Finally, it provides the results of regressing real market returns on real $I C C$, where the real $I C C$ is the difference between our main measure of the aggregate $I C C$ and the one-month inflation rate, and the real market returns are the difference between the monthly continuously compounded nominal returns and the one-month inflation rate. Panel $\mathrm{C}$ investigates whether the predictive power of $I R P$ is due to analysts forecast optimism, where $A E$ is our measure of aggregate analyst forecast optimism. Panel $\mathrm{C} 1$ reports the univariate regression of $A E$, and Panel $\mathrm{C} 2$ reports the bivariate regression of IRP and $A E$. The dependent variable in these regressions is the continuously compounded excess return per month defined as the difference between the monthly continuously compounded return on the value-weighted market return including dividends from WRDS and the monthly continuously compounded one-month T-bill rate. All regressions use data from January 1977 to December 2011. $K$ is the forecasting horizon in months. In forecasting horizons beyond one-month, the regressions use overlapping observations. $b$ and $c$ are the slope coefficients from the OLS regressions. avg. is the average slope coefficient. $Z(b)$ and $Z(b)$ are the asymptotic $Z$-statistics computed using the GMM standard errors with $K-1$ Newey-West lag correction. These standard errors correct for the autocorrelation in regressions due to overlapping observations and for generalized conditional heteroskedasticity. The adj. $R^{2}$ is obtained from the OLS regression. The $p$-values of $Z$-statistics and the average slope coefficient are obtained by comparing the test statistics with their empirical distribution generated under the null of no predictability from 5,000 trials of a Monte Carlo simulation. The artificial data for the simulation are generated under the null using the VAR approach described in Appendix B.

Panel A: The Role of Growth Forecast

\begin{tabular}{|c|c|c|c|c|c|c|c|c|c|c|c|}
\hline \multicolumn{5}{|c|}{ Panel A1: Univariate Regression of $F E_{1} / P$} & \multicolumn{7}{|c|}{ Panel A2: Bivariate Regression Involving $I R P$ and $F E_{1} / P$} \\
\hline & \multicolumn{4}{|c|}{$F E_{1} / P$} & \multicolumn{3}{|c|}{$\operatorname{IRP}$} & \multicolumn{3}{|c|}{$F E_{1} / P$} & \multirow[b]{2}{*}{$\operatorname{adj} . R^{2}$} \\
\hline$K$ & $b$ & $Z(b)$ & pval & $\operatorname{adj} . R^{2}$ & $b$ & $Z(b)$ & pval & $c$ & $Z(c)$ & pval & \\
\hline 1 & 0.609 & 0.641 & 0.481 & 0.001 & 1.970 & 1.771 & 0.062 & 0.231 & 0.241 & 0.578 & 0.005 \\
\hline 12 & 0.949 & 1.251 & 0.366 & 0.028 & 1.469 & 2.068 & 0.097 & 0.665 & 0.941 & 0.389 & 0.075 \\
\hline 24 & 0.763 & 1.145 & 0.429 & 0.043 & 1.657 & 2.757 & 0.058 & 0.428 & 0.959 & 0.409 & 0.181 \\
\hline 36 & 0.716 & 1.265 & 0.428 & 0.067 & 1.655 & 3.476 & 0.036 & 0.358 & 1.134 & 0.386 & 0.278 \\
\hline 48 & 0.651 & 1.460 & 0.414 & 0.085 & 1.429 & 4.150 & 0.027 & 0.344 & 1.401 & 0.358 & 0.324 \\
\hline avg. & 0.738 & & 0.484 & & 1.636 & & 0.040 & 0.405 & & 0.525 & \\
\hline
\end{tabular}




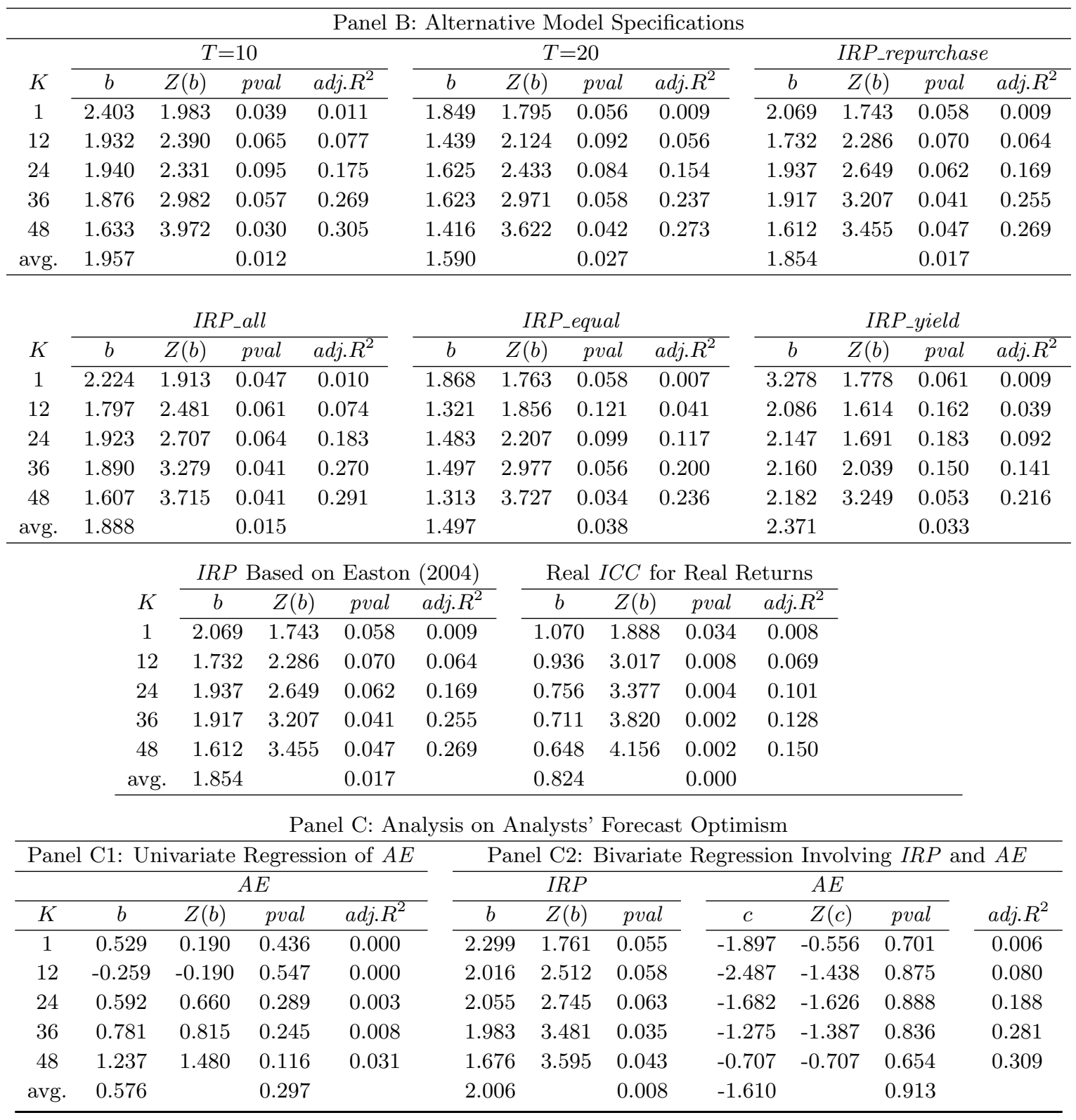




\section{Table 6 Analysis Using Hodrick (1992) Standard Errors}

Panel A of this table provides two $Z$-statistics of univariate regressions of equation (8) for $I R P$ and $D / P$. $Z(b)$ is the $Z$-statistics based on the Newey-West standard errors, and $Z(b)^{h d}$ is the $Z$-statistics based on the Hodrick (1992) standard errors. $95 \%$ and $95 \%^{h d}$ are the 95 th percentile of the empirical distributions from the Monte Carlo simulations conducted under the null hypothesis (Appendix B) for $Z(b)$ and $Z(b)^{h d}$, respectively. Panels $\mathrm{B}$ and $\mathrm{C}$ report the univariate regressions and bivariate regressions of equation (8) when the $Z$-statistics are calculated based on Hodrick (1992) standard errors $Z(b)^{h d}$. The dependent variable in these regressions is the continuously compounded excess return per month defined as the difference between the monthly continuously compounded return on the value-weighted market return including dividends from WRDS and the monthly continuously compounded one-month T-bill rate. The independent variable in Panel $\mathrm{B}$ is $I R P, D / P, E / P$, or $B / M$, and the independent variables in Panel $\mathrm{C}$ are $I R P$ and $D / P, I R P$ and $E / P$, or $I R P$ and $B / M$. Since our dependent variable is average monthly excess returns, we divide $I R P, D / P, E / P$, and $B / M$ also by 12 . This rescaling does not affect the significance of the slopes. All regressions use monthly data from January 1977 to December 2011. $K$ is the forecasting horizon in months. In forecasting horizons beyond one-month, the regressions use overlapping observations. $b$ and $c$ are the slope coefficients from the OLS regressions. avg. is the average slope coefficient. $Z(b)^{h d}$ and $Z(c)^{h d}$ are the asymptotic $Z$-statistics computed using the Hodrick (1992) standard errors. The adj. $R^{2}$ is obtained from the OLS regression. The $p$-values of $Z(b)^{h d}$ and $Z(c)^{h d}$ (pval ${ }^{h d}$ ) and the average slope coefficient are obtained by comparing the test statistics with their empirical distribution generated under the null of no predictability from 5,000 trials of a Monte Carlo simulation. The artificial data for the simulation are generated under the null using the VAR approach described in Appendix B.

\begin{tabular}{|c|c|c|c|c|c|c|c|c|c|c|}
\hline & \multicolumn{10}{|c|}{ Panel A: $Z$-Statistics and Simulated $95 \%$ Critical Values for $I R P$ and $D / P$} \\
\hline & \multicolumn{5}{|c|}{$I R P$} & \multicolumn{5}{|c|}{$D / P$} \\
\hline$K$ & $b$ & $Z(b)$ & $95 \%$ & $Z(b)^{h d}$ & $95 \%^{h d}$ & $b$ & $Z(b)$ & $95 \%$ & $Z(b)^{h d}$ & $95 \%^{h d}$ \\
\hline 1 & 2.023 & 1.849 & 1.865 & 1.849 & 1.865 & 3.423 & 1.298 & 2.090 & 1.298 & 2.090 \\
\hline 12 & 1.627 & 2.295 & 2.639 & 1.680 & 1.941 & 3.424 & 1.594 & 3.043 & 1.311 & 2.196 \\
\hline 24 & 1.772 & 2.522 & 2.908 & 2.135 & 1.989 & 2.744 & 1.384 & 3.522 & 1.085 & 2.236 \\
\hline 36 & 1.773 & 3.175 & 3.125 & 2.146 & 2.011 & 2.247 & 1.421 & 4.110 & 0.928 & 2.249 \\
\hline 48 & 1.546 & 3.900 & 3.421 & 2.539 & 2.097 & 2.236 & 1.875 & 4.519 & 0.940 & 2.363 \\
\hline
\end{tabular}

Panel B: Univariate Regression Based on Hodrick (1992) Standard Errors

\begin{tabular}{|c|c|c|c|c|c|c|c|c|}
\hline \multirow[b]{2}{*}{$K$} & \multicolumn{4}{|c|}{$I R P$} & \multicolumn{4}{|c|}{$D / P$} \\
\hline & $b$ & $Z(b)^{h d}$ & pval $^{h d}$ & adj. $R^{2}$ & $b$ & $Z(b)^{h d}$ & $p_{v a l}^{h d}$ & $\operatorname{adj.} R^{2}$ \\
\hline 1 & 2.023 & 1.849 & 0.052 & 0.009 & 3.423 & 1.298 & 0.221 & 0.004 \\
\hline 12 & 1.627 & 1.680 & 0.084 & 0.066 & 3.424 & 1.311 & 0.233 & 0.046 \\
\hline 24 & 1.772 & 2.135 & 0.039 & 0.173 & 2.744 & 1.085 & 0.316 & 0.070 \\
\hline 36 & 1.773 & 2.146 & 0.039 & 0.267 & 2.247 & 0.928 & 0.385 & 0.084 \\
\hline 48 & 1.546 & 2.539 & 0.022 & 0.305 & 2.236 & 0.940 & 0.391 & 0.128 \\
\hline \multirow[t]{2}{*}{ avg. } & 1.748 & & 0.020 & & 2.815 & & 0.349 & \\
\hline & \multicolumn{4}{|c|}{$E / P$} & \multicolumn{4}{|c|}{$B / M$} \\
\hline$K$ & $b$ & $Z(b)^{h d}$ & $p_{v a l}{ }^{h d}$ & $a d j \cdot R^{2}$ & $b$ & $Z(b)^{h d}$ & $p_{v a l}^{h d}$ & $a d j . R^{2}$ \\
\hline 1 & 1.196 & 1.058 & 0.320 & 0.003 & 0.158 & 1.036 & 0.365 & 0.003 \\
\hline 12 & 1.131 & 1.090 & 0.318 & 0.030 & 0.169 & 1.135 & 0.333 & 0.034 \\
\hline 24 & 0.890 & 0.899 & 0.402 & 0.043 & 0.130 & 0.882 & 0.443 & 0.048 \\
\hline 36 & 0.709 & 0.728 & 0.479 & 0.048 & 0.112 & 0.794 & 0.490 & 0.062 \\
\hline 48 & 0.664 & 0.652 & 0.518 & 0.066 & 0.103 & 0.744 & 0.522 & 0.081 \\
\hline avg. & 0.918 & & 0.441 & & 0.134 & & 0.519 & \\
\hline
\end{tabular}




\begin{tabular}{|c|c|c|c|c|c|c|c|}
\hline Pane & Bivar & ate Reg & ssion B & on $\mathrm{F}$ & drick ( & 92) Sta & Errors \\
\hline & & $I R P$ & & & $D / P$ & & \\
\hline$K$ & $b$ & $Z(b)^{h d}$ & pval $^{h d}$ & $c$ & $Z(c)^{h d}$ & pval $^{h d}$ & $a d j . R^{2}$ \\
\hline 1 & 1.794 & 1.584 & 0.100 & 2.236 & 0.824 & 0.325 & 0.006 \\
\hline 12 & 1.348 & 1.408 & 0.133 & 2.455 & 0.947 & 0.287 & 0.084 \\
\hline 24 & 1.571 & 2.051 & 0.041 & 1.523 & 0.625 & 0.409 & 0.188 \\
\hline 36 & 1.623 & 2.056 & 0.049 & 1.007 & 0.417 & 0.485 & 0.278 \\
\hline 48 & 1.362 & 1.922 & 0.069 & 1.163 & 0.445 & 0.474 & 0.332 \\
\hline avg. & 1.539 & & 0.045 & 1.677 & & 0.416 & \\
\hline & & $I R P$ & & & $E / P$ & & \\
\hline$K$ & $b$ & $Z(b)^{h d}$ & pval ${ }^{h d}$ & $c$ & $Z(c)^{h d}$ & pval $^{h d}$ & $a d j . R^{2}$ \\
\hline 1 & 1.870 & 1.703 & 0.085 & 0.789 & 0.703 & 0.381 & 0.006 \\
\hline 12 & 1.462 & 1.533 & 0.120 & 0.806 & 0.796 & 0.354 & 0.076 \\
\hline 24 & 1.655 & 2.111 & 0.047 & 0.500 & 0.526 & 0.444 & 0.181 \\
\hline 36 & 1.689 & 2.126 & 0.051 & 0.349 & 0.364 & 0.510 & 0.274 \\
\hline 48 & 1.459 & 2.250 & 0.043 & 0.365 & 0.346 & 0.524 & 0.320 \\
\hline avg. & 1.627 & & 0.043 & 0.562 & & 0.478 & \\
\hline & & $I R P$ & & & $B / M$ & & \\
\hline$K$ & $b$ & $Z(b)^{h d}$ & $p v a l^{h d}$ & $c$ & $Z(c)^{h d}$ & pval $^{\text {hd }}$ & $a d j . R^{2}$ \\
\hline 1 & 1.870 & 1.655 & 0.089 & 0.079 & 0.506 & 0.510 & 0.005 \\
\hline 12 & 1.407 & 1.464 & 0.130 & 0.109 & 0.740 & 0.415 & 0.075 \\
\hline 24 & 1.641 & 2.136 & 0.036 & 0.059 & 0.418 & 0.531 & 0.177 \\
\hline 36 & 1.673 & 2.113 & 0.042 & 0.039 & 0.280 & 0.584 & 0.270 \\
\hline 48 & 1.441 & 2.031 & 0.055 & 0.040 & 0.263 & 0.601 & 0.312 \\
\hline avg. & 1.607 & & 0.048 & 0.065 & & 0.563 & \\
\hline
\end{tabular}




\section{Table 7 Out-of-Sample Test}

This table summarizes the out-of-sample analysis of forecasting models using different forecasting variables. Panel A reports the $R_{o s}^{2}$ statistic of Campbell and Thompson (2008). Statistical significance of $R_{o s}^{2}$ is obtained based on the $p$-value for the Clark and West (2007) out-of-sample adjusted-MSPE statistic; the statistic corresponds to a one-sided test of the null hypothesis that the competing forecasting model using a specific forecasting variable has equal expected squared prediction error relative to the historical average forecasting model against the alternative that the competing model has a lower expected squared prediction error than the historical average benchmark model. Panel A also reports the utility gain (Ugain), which is the portfolio management fee (in annualized percentage return) that an investor with mean-variance preferences and risk aversion coefficient of three would be willing to pay to have access to the forecasting model using a particular forecasting variable relative to the historical average benchmark forecasting model; the weight on stocks in the investor's portfolio is constrained to lie between zero and 1.5 (inclusive). Panel B reports the $p$-values of the forecasting encompassing test statistic of Harvey, Leybourne, and Newbold (1998) (HLN statistic). The HLN statistic corresponds to a one-sided (upper-tail) test of the null hypothesis that the forecast from the row variable $(\mathrm{R})$ encompasses the forecast from the column variable $(\mathrm{C})$ against the alternative hypothesis that the forecast from the row variable $(\mathrm{R})$ does not encompass the forecast from the column variable (C). We consider two forecast periods, namely, January 1998-December 2011 and January 2003-December 2011. The dependent variable in these regressions is the continuously compounded excess return per month defined as the difference between the monthly continuously compounded return on the value-weighted market return including dividends from WRDS and the monthly continuously compounded one-month T-bill rate. In these tests, we perform a 2-year moving average for $I R P, D / P, E / P$, and $B / M$.

\begin{tabular}{|c|c|c|c|c|c|c|}
\hline \multicolumn{7}{|c|}{ Panel A: Out-of-Sample $R_{o s}^{2}$ and Utility Gains } \\
\hline & \multirow{2}{*}{\multicolumn{3}{|c|}{$\begin{array}{l}\text { Forecast Period: } \\
\text { 1998.01-2011.12 }\end{array}$}} & \multirow{2}{*}{\multicolumn{3}{|c|}{$\begin{array}{l}\text { Forecast Period: } \\
\text { 2003.01-2011.12 }\end{array}$}} \\
\hline & & & & & & \\
\hline & $R_{o s}^{2}$ & pval & Ugain & $R_{o s}^{2}$ & pval & Ugain \\
\hline $\operatorname{IRP}$ & 1.22 & 0.06 & 4.15 & 1.61 & 0.09 & 5.44 \\
\hline$D / P$ & 0.44 & 0.16 & 1.38 & -0.07 & & 0.35 \\
\hline$E / P$ & 0.22 & 0.27 & 0.40 & -0.66 & & -1.71 \\
\hline$B / M$ & 0.26 & 0.23 & 0.57 & -0.29 & & -0.65 \\
\hline Term & -0.53 & & -1.32 & -0.51 & & -1.46 \\
\hline Default & -0.90 & & -1.33 & -1.65 & & -2.00 \\
\hline Tbill & -1.18 & & -2.21 & -0.55 & & -1.40 \\
\hline Yield & -1.62 & & -1.84 & -0.54 & & -0.72 \\
\hline
\end{tabular}


Panel B: Forecast Encompassing Test

Forecast Period: 1998.01-2011.12

\begin{tabular}{ccccccccc}
\hline & \multicolumn{8}{c}{ Column Variables $(\mathrm{C})$} \\
\cline { 5 - 9 } Row Variables (R) & IRP & $E / P$ & $D / P$ & $B / M$ & Term & Default & Tbill & Yield \\
\cline { 1 - 6 }$I R P$ & & 0.40 & 0.50 & 0.51 & 0.76 & 0.71 & 0.84 & 0.79 \\
$E / P$ & 0.09 & & 0.70 & 0.70 & 0.71 & 0.74 & 0.73 & 0.76 \\
$D / P$ & 0.07 & 0.23 & & 0.41 & 0.69 & 0.69 & 0.73 & 0.73 \\
$B / M$ & 0.07 & 0.22 & 0.55 & & 0.73 & 0.73 & 0.77 & 0.77 \\
Term & 0.03 & 0.07 & 0.10 & 0.09 & & 0.53 & 0.74 & 0.66 \\
Default & 0.04 & 0.11 & 0.16 & 0.14 & 0.29 & & 0.44 & 0.51 \\
Tbill & 0.01 & 0.03 & 0.04 & 0.03 & 0.10 & 0.28 & & 0.67 \\
Yield & 0.01 & 0.02 & 0.04 & 0.03 & 0.09 & 0.18 & 0.19 & \\
\hline
\end{tabular}

Forecast Period: 2003.01-2011.12

\begin{tabular}{ccccccccc}
\hline & \multicolumn{7}{c}{ Column Variables $(\mathrm{C})$} \\
\cline { 5 - 9 } Row Variables (R) & IRP & $E / P$ & $D / P$ & $B / M$ & Term & Default & Tbill & Yield \\
\cline { 1 - 6 }$I R P$ & & 0.43 & 0.58 & 0.54 & 0.67 & 0.65 & 0.69 & 0.61 \\
$E / P$ & 0.07 & & 0.83 & 0.64 & 0.50 & 0.65 & 0.40 & 0.43 \\
$D / P$ & 0.05 & 0.13 & & 0.15 & 0.30 & 0.56 & 0.27 & 0.29 \\
$B / M$ & 0.06 & 0.28 & 0.83 & & 0.47 & 0.64 & 0.39 & 0.42 \\
Term & 0.07 & 0.21 & 0.43 & 0.29 & & 0.63 & 0.39 & 0.35 \\
Default & 0.06 & 0.19 & 0.27 & 0.22 & 0.22 & & 0.21 & 0.21 \\
Tbill & 0.06 & 0.17 & 0.34 & 0.22 & 0.33 & 0.61 & & 0.43 \\
Yield & 0.06 & 0.16 & 0.37 & 0.24 & 0.31 & 0.64 & 0.45 & \\
\hline
\end{tabular}




\section{Table A1 Phillips-Perron Unit Root Tests}

This table summarizes the results of Phillips-Perron unit root tests on the forecasting variables. IRP, $D / P$, E/P, B/M, Term, Default, Tbill, and Yield are monthly data from January 1977 to December 2011, P/Y, ntis, infl, svar, Lagged Vwretd, and senti are monthly data from January 1977 to December 2010, and cay and $i / k$ are quarterly data from 1977.Q1 to 2008.Q4. Two types of unit root tests specified in equation (15) are performed. $T$ is the number of observations. The Phillips-Perron test allows for regression errors to be serially correlated and heteroskedastic. The test statistics are computed using serial correlation up to twelve lags in the regression residuals. ${ }^{*}, * *$, and ${ }^{* * *}$ indicate significance at the $10 \%, 5 \%$, and $1 \%$ level, respectively.

\begin{tabular}{cccc}
\hline Variables & without Time Trend & with Time Trend & $T$ \\
\hline IRP & $-20.52^{* * *}$ & $-20.63^{*}$ & 420 \\
$D / P$ & -4.49 & -15.73 & 420 \\
$E / P$ & -6.05 & -11.48 & 420 \\
$B / M$ & -3.95 & -7.01 & 420 \\
$P / Y$ & -10.20 & -13.87 & 408 \\
Term & $-34.49^{* * *}$ & $-38.84^{* * *}$ & 420 \\
Default & $-20.15^{* *}$ & $-20.80^{*}$ & 420 \\
Tbill & -7.85 & $-32.69^{* * *}$ & 420 \\
Yield & -2.43 & $-18.83^{*}$ & 420 \\
ntis & $-127.89^{* * *}$ & $-177.33^{* * *}$ & 408 \\
infl & $-192.01^{* * *}$ & $-227.33^{* * *}$ & 408 \\
svar & $-280.11^{* * *}$ & $-278.55^{* * *}$ & 408 \\
Lagged Vwretd & $-352.31^{* * *}$ & $-351.74^{* * *}$ & 408 \\
senti & $-14.61^{* *}$ & -14.41 & 408 \\
cay & -7.90 & -8.21 & 128 \\
i/k & -9.84 & -10.03 & 128 \\
\hline
\end{tabular}



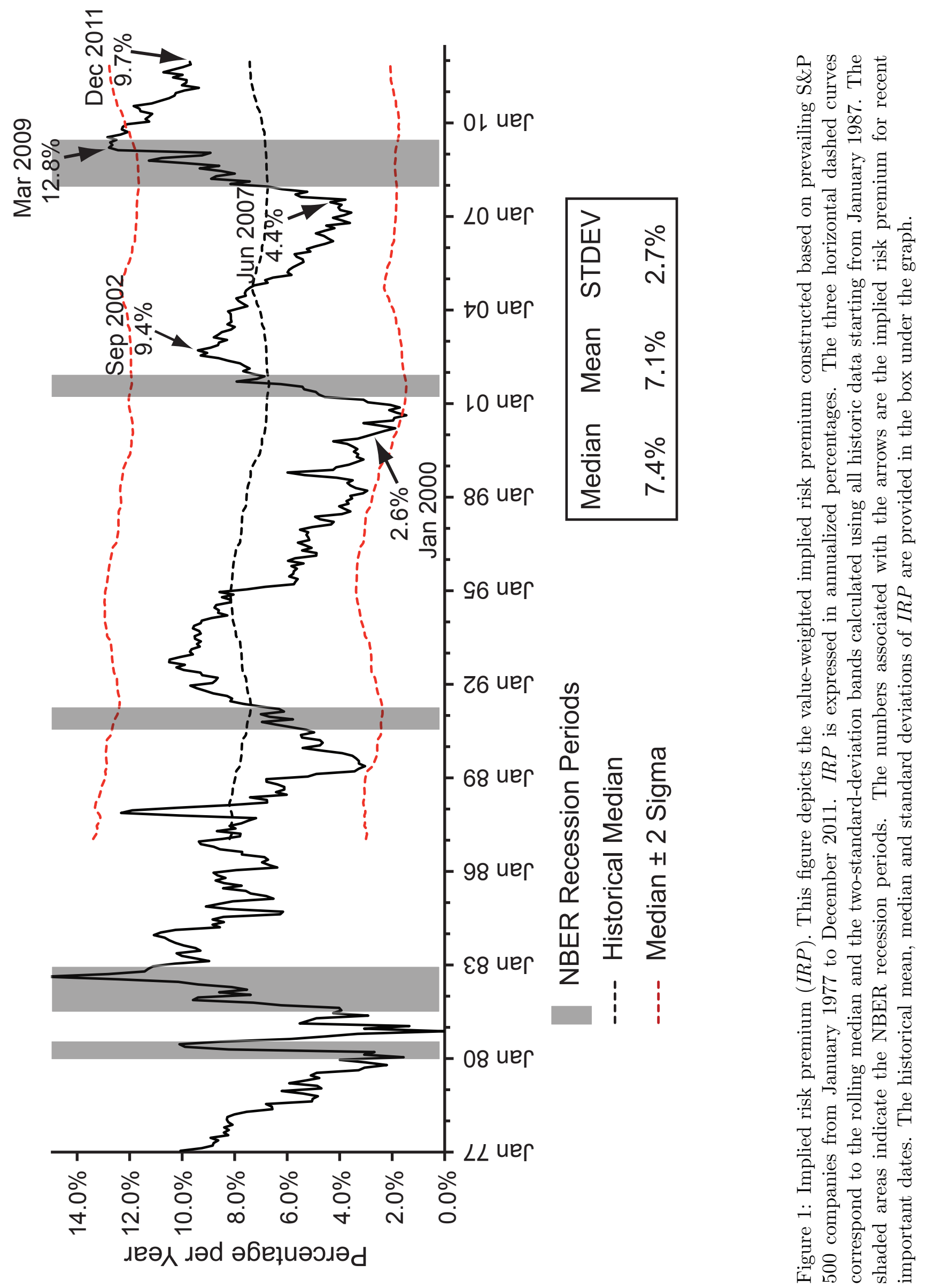

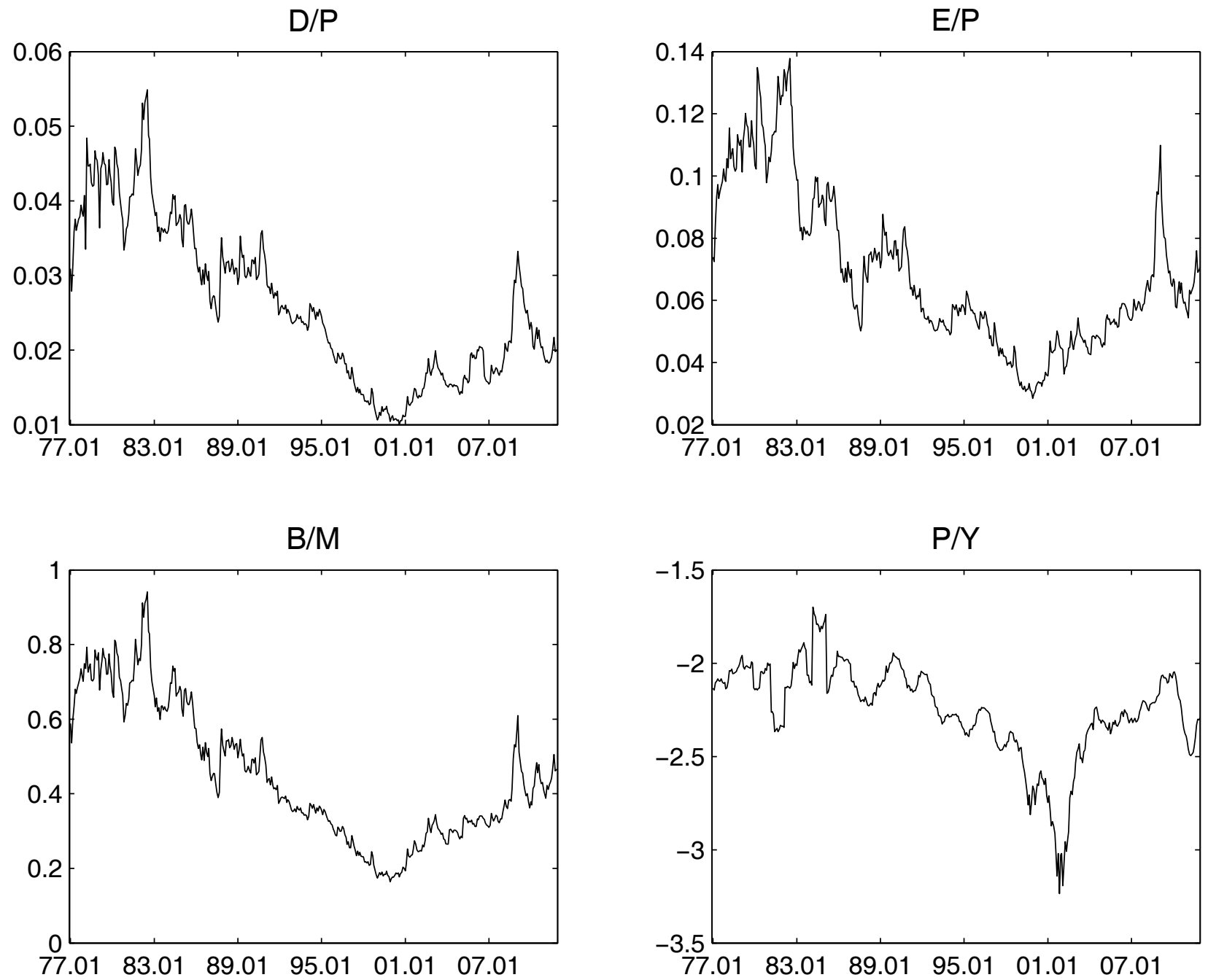

Figure 2: Time series of valuation ratios. This figure depicts the dividend-to-price ratio $(D / P)$, earnings-to-price ratio $(E / P)$, and book-to-market ratio $(B / M)$ from January 1977 to December 2011, and the payout yield $(P / Y$, in logarithm) from January 1977 to December 2010. 

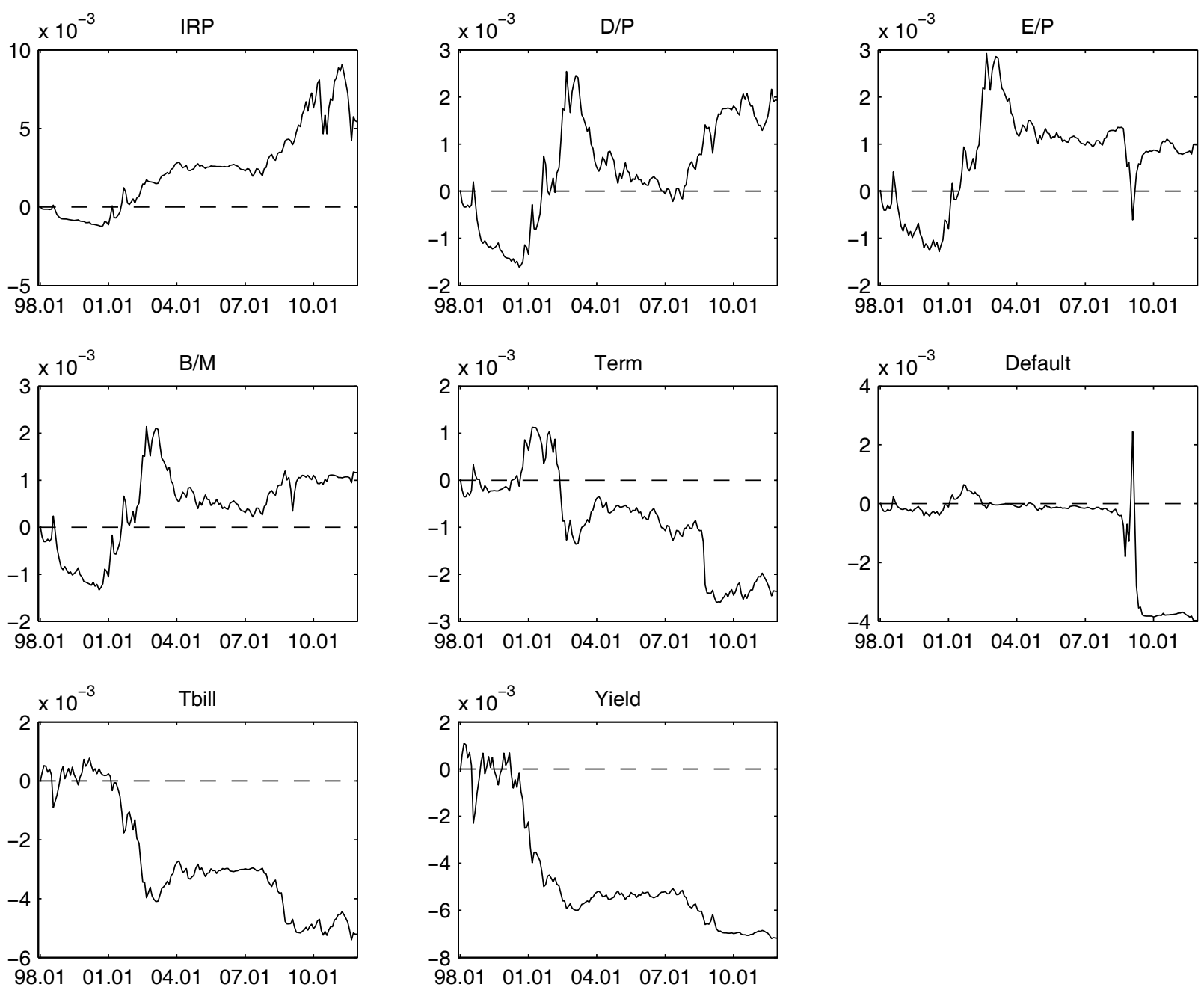

Figure 3: Cumulative squared prediction error for the historical average benchmark forecasting model minus the cumulative squared prediction error for the forecasting model using the implied risk premium $(I R P)$, dividend-to-price ratio $(D / P)$, earnings-to-price ratio $(E / P)$, book-to-market ratio $(B / M)$, term spread (Term), default spread (Default), T-bill rate ( $T b i l l)$, and 30-year treasury yield ( Yield), during the forecast period of January 1998-December 2011. The dotted line in each panel goes through zero. 